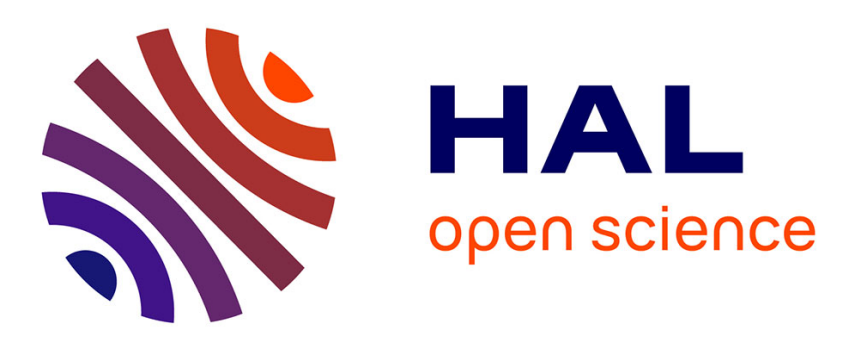

\title{
AN OVERVIEW OF THE ELECTROCHEMICAL INTERFACE AND OPTICAL SPECTROSCOPIC STUDIES
}

\author{
E. Yeager
}

\section{- To cite this version:}

E. Yeager. AN OVERVIEW OF THE ELECTROCHEMICAL INTERFACE AND OPTICAL SPECTROSCOPIC STUDIES. Journal de Physique Colloques, 1977, 38 (C5), pp.C5-1-C5-17. 10.1051/jphyscol:1977501 . jpa-00217148

\section{HAL Id: jpa-00217148 \\ https://hal.science/jpa-00217148}

Submitted on 1 Jan 1977

HAL is a multi-disciplinary open access archive for the deposit and dissemination of scientific research documents, whether they are published or not. The documents may come from teaching and research institutions in France or abroad, or from public or private research centers.
L'archive ouverte pluridisciplinaire HAL, est destinée au dépôt et à la diffusion de documents scientifiques de niveau recherche, publiés ou non, émanant des établissements d'enseignement et de recherche français ou étrangers, des laboratoires publics ou privés. 


\title{
AN OVERVIEW OF THE ELECTROCHEMICAL INTERFACE AND OPTICAL SPECTROSCOPIC STUDIES
}

\author{
E. YEAGER \\ Case Laboratories for Electrochemical Studies and the Chemistry Department, \\ Case Western Reserve University, Cleveland, Ohio 44106, U.S. A.
}

\begin{abstract}
Résumé. - Cet article passe en revue l'état actuel des connaissances sur la structure de l'interface électrochimique et décrit le type d'informations que peut supporter à cette connaissance les études d'optique spectroscopique. Parmi les problèmes les plus difficiles à résoudre se trouvent la détermination de la structure du solvant dans la couche compacte et la nature des interactions des espèces adsorbées avec la surface de l'électrođe. Jusqu'à maintenant il faut dire que peu d'informations ont été obtenues à partir des mesures optiques.
\end{abstract}

\begin{abstract}
This paper reviews the present understanding of the structure of electrochemical interfaces and identifies the types of information which optical spectroscopic information may be able to contribute. Particularly challenging problems are the structure of the solvent in the compact layer and the nature of the interactions of adsorbed species with the electrode surface. So far, little information has been derived from optical measurements concerning these problems.
\end{abstract}

1. Introduction. - The purpose of this lecture is two-fold :1) to review the present understanding of the structure of electrochemical interfaces; and 2) to identify the types of information which optical measurements may be able to contribute.

The structure of the electrochemical interface is a particularly challenging problem. A quantitative description is essential to the orderly development of electrochemical surface science and yet even the qualitative description of the interface remains in doubt, despite a very substantial literature on this topic (for review see ref. [1-3]). Electrochemical interfaces usually involve steep potential gradients and strong interactions of the solvent and other electrolyte phase species with the metal or semiconductor electrode surface as well as with other electrolyte phase components. This means that discrete charge effects and discrete interactions must be taken into account in any reliable theoretical model. On the other hand, very little information is available concerning the chemical interactions of the adsorbed species with the electrode and the adsorption sites. The extrapolation of solidgas information concerning interaction energies, configurations and adsorption sites to electrochemical interfaces is precarious since the interactions of the various adsorbed species with the electrolyte phase components (particularly the solvent) are usually strong.

Part of the problem is a general lack of good molecularly specific experimental techniques for examining the chemical structures of electrochemical interfaces, analogous to the various spectroscopic techniques which have proved so helpful in establishing the mole- cular structure and interaction chemistry in the bulk gas and condensed phases. In many instances electrochemical measurements provide sensitive tools for the detection of changes in the structure of the electrochemical interface and particularly the adsorption of various species even down to small fractions of a monoloyer, but they lack the needed molecular level specificity to identify the nature of the surface interactions. Even the charge on electrosorbed species cannot be determined electrochemically because of the difficulty of resolving what fraction of the externally provided charge is transferred to the adsorbed species rather than just residing on the metal surface, compensating the charge of the electrosorbed species and the remainder of the ionic double layer (see, e. g., ref. [4-8])

The most promising general experimental approach for obtaining molecular level information is in situ optical spectroscopy. Tables I and II summarize the various optical spectroscopic techniques which are available for in situ studies of electrochemical interfaces and the types of information which the electrochemist may hope to derive from such measurements. The literature contains reports of the use of all of these methods with some degree of success in electrochemical studies with the exception of photoacousticspectroscopic $\left(^{1}\right)$.

(1) Photoacoustic spectroscopy involves the determination of the optical absorption spectrum of surface layers by illuminating the surface with modulated monochromatic lighth and then detecting the optical absorption through the thermally generated sound in the ambient phase as a function of optical wavelength. This method lends itself to surfaces of very poor optical quality such as high area catalyst layers and should prove useful for examining the valency state of various electrocatalysts. 


\section{TABLE I}

In situ optical spectroscopic techniques for the study of electrochemical interfaces

1. Specular reflectance spectroscopy and ellipsometry : external, internal.

2. Diffuse reflectance spectroscopy. tes).

4. Raman (including resonant Raman).

5. Surface Brillouin scattering.

6. Photoacoustic spectroscopy.

7. Photon-assisted charge transfer.

\section{TABle II}

\section{Types of information from optical studies} of electrochemical surfaces

1. Electronic surface properties : metal and semiconductor electrodes.

2. Adsorption of electrolyte phase species

- type of bonding,

- adsotption isotherms,

- adsorption kinetics.

3. Passivation and other multilayers

- structure, thickness,

- kinetics of formation and removal.

4. Battery cathodes

- valency state,

- composition.

5. Reaction intermediates

- identification,

- quantitative analyses.

6. Identification of surface groups on electrode surfaces (e. g. carbons, graphites, compound semiconductors, chemically modified surfaces).

Ultraviolet and visible reflectance spectroscopy including ellipsometric spectroscopy are sensitive to the surface electronic properties of metal and semiconductors and changes in these properties produced by interactions with various species originating from the electrolyte phase. Ultraviolet-visible spectroscopy can also provide chemical information concerning catalyst layers, passivation layers and in general the various mono- and multi-layers which play a critical role in controlling electrochemical processes. A number of electrochemists have made use of these optical techniques to study electrochemical interfaces and particularly electrosorption and passivation over the past decade. To date these studies have contributed relatively little further understanding concerning the electronic-chemical features of the interface. Substantial information is contained in the UV-visible reflectance and ellipsometric data ; the problem is to extract and interpret this information. This problem is not restricted to electrochemical interfaces.

Vibrational data for adsorbed species including water itself would be quite helpful. In situ infrared studies have been carried out $[10,11]$ using multiple attenuated total reflection techniques and infrared transparent electrode substrates, but have not yielded much information concerning adsorbed species. Solvent absorption and sensitivity have been serious problems. In situ Raman $[13 a, b, c]$, including resonant Raman $[14,15]$ where applicable may prove more promising for studies of adsorbed species, particularly since water is not a problem.

It is unfortunate that the elegant surface physics techniques such as LEED, UPS, XPS and Auger cannot be applied in situ to electrochemical studies. Even so, efforts are in progress to use these techniques ex situ in electrochemical studies with special procedures for minimizing structural changes during the transfer between the electrochemical and high vacuum environments [16-21]. Despite the special features of electrochemical interfaces, parallel solid-gas and electrode-electrolyte interface studies should prove quite helpful in better understanding electrochemical interfaces.

2. Basic structural features of electrochemical interfaces. - 2.1 THE DIfFuse LAYER. - The ionic double layer on the electrolyte side of the electrochemical interface is considered to consist of two regions : a Helmholtz or compact layer across which most of the potential drop occurs, and a diffuse ionic layer (GouyChapman) extending out into the electrolyte phas (see Fig. 1a). The diffuse ionic layer presents no problem for solutions sufficiently dilute that point charge treatments in a dielectric continuum are applicable (see ref. [1-3, 42]). For a symmetrical electrolyte $\left(z_{+}=\left|z_{-}\right|=z\right)$, the potential distribution is given by

$$
\varphi=\frac{4 k T}{z e} \tanh ^{-1}\{\exp [p-\kappa x]\}
$$

where the Debye reciprocal length $\kappa$ is given by

$$
\kappa^{2}=\frac{8 \pi z^{2} e^{2}}{\varepsilon k T} c
$$

and

$$
p=\ln \tanh \left[\frac{z e \varphi_{2}}{4 k T}\right]+\kappa x_{2} .
$$

$\varepsilon$ is the dielectric constant of the solvent, $c$ is the bulk concentration of the electrolyte and the subscript 2 corresponds to the plane of closest approach of the solvated ions to the electrode surface, i. e. the outer Helmholtz plane (see Fig. 2). For large values of $x-x_{2}$, the potential dependence approaches the form

$$
\varphi=A \exp (-\kappa x) .
$$

In electrochemical reactions, the position $x_{2}$ is often considered as the pre-reaction state for non-specifically adsorbed species prior to the charge transfer process. The concentration of charged reacting species in this plane can be calculated from $\varphi_{2}$. Further the potential 


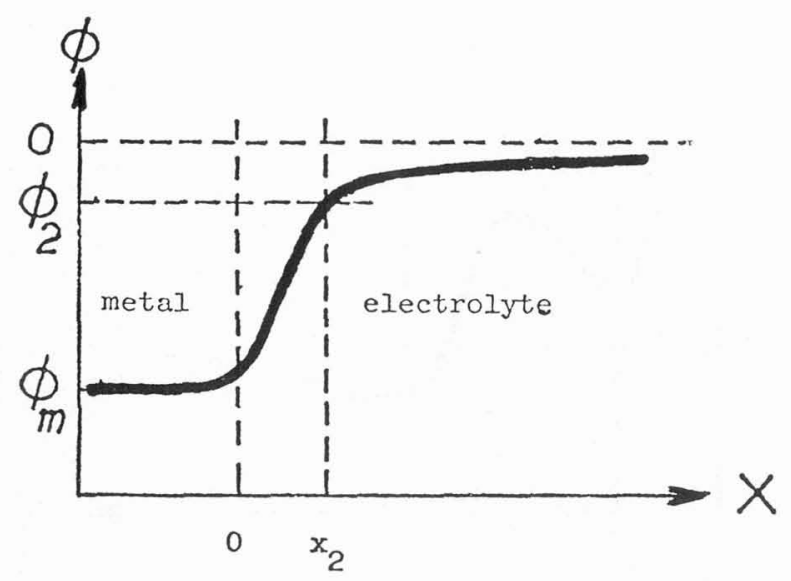

a. without specific ionic adsorption

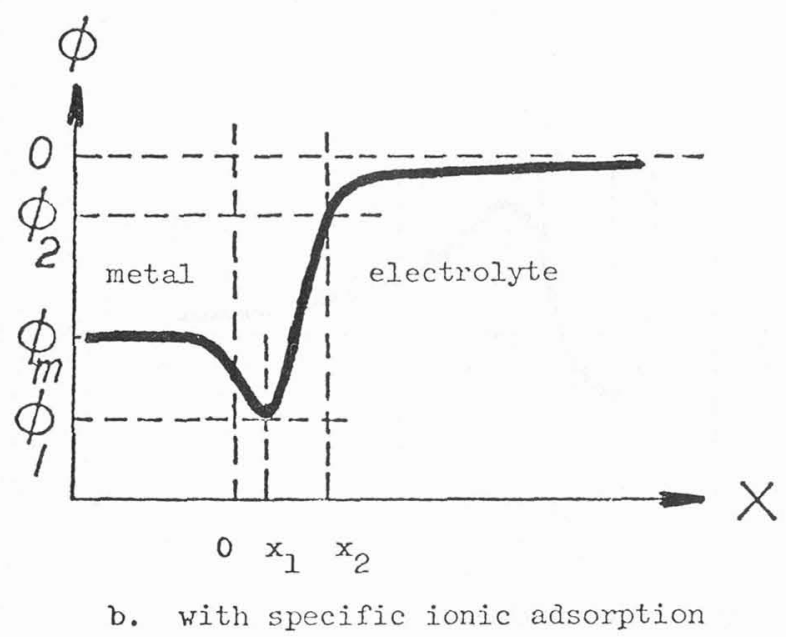

Frg. 1. - Potential distribution across the electrochemical surface and without ionic specific adsorption. Region I : Helmholtz layer (compact). Region II : Gouy-Chapman layer (diffuse). $x_{2}$-distance of closest approach without specific adsorption. $x_{1}$-distance of closest approach of specifically adsorbed ion. a) without specific ionic adsorption; $b$ ) with specific ionic adsorption.

drop across the Helmholtz layer $\left(\varphi_{m}-\varphi_{2}\right)$ controls the height of the potential energy barrier for the charge transfer process. Consequently $\varphi_{2}$ is needed in order to correct for ionic double layer effects in electrode kinetic studies. This potential can be calculated from the net charge, $q$, in the ionic double layer in the absence of specific ionic adsorption using the equation

$$
q=\left(q_{+}\right)_{2-s}+\left(q_{-}\right)_{2-s}
$$

where

$\left(q_{+}\right)_{2-s}=\left(\frac{R T \varepsilon}{2 \pi} c\right)^{1 / 2}\left[\exp -\frac{z_{+} \varepsilon \varphi_{2}}{2 k T}-1\right]$

and

$\left(q_{-}\right)_{2-s}=-\left(\frac{R T \varepsilon}{2 \pi} c\right)^{1 / 2}\left[\exp -\frac{z_{-} \varepsilon \varphi_{2}}{2 k T}-1\right]$.

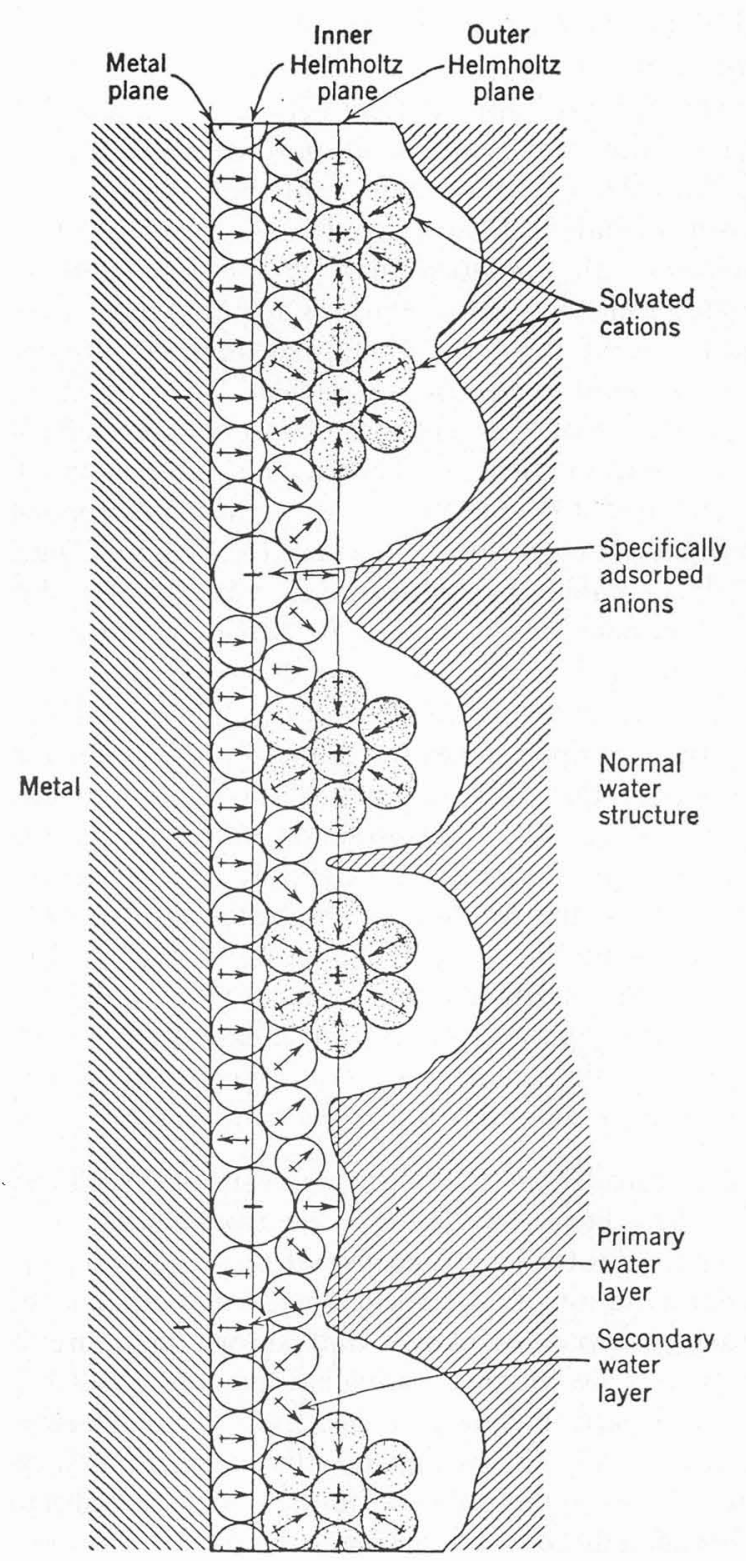

FIG. 2. - The model for the ionic double layer of Bockris, Devanathan and Muller (22).

The charge $q$ can be determined from experimental data for the differential capacitance $C$ using the equation

$$
q=\int_{E_{p z c}}^{E} C \mathrm{~d} E
$$

where $E$ is the electrode potential relative to a reference electrode and $E_{\mathrm{pzc}}$ is the corresponding value when $q=0$, i. e. the potential of zero charge (pzc). At the pzc, the potential drop across the interface should be only that associated with the surface dipoles and hence close to zero. Alternatively, with liquid metal electrodes the charge $q$ can also be evaluated from the interfacial tension $\gamma$ using the Lippmann equation [27]

$$
q=-(\partial \gamma / \partial E)_{\mu_{t}}
$$


with the chemical potentials of all bulk components kept constant.

The Gouy-Chapman treatment is a dilute solution theory and breaks down at practical concentrations $(\geqslant 0.1 \mathrm{M})$. Factors which contribute to this breakdown include the non-ideality of the solvent as a dielectric, the polarizability of the ions and short range repulsion effects. Various workers have attempted to extend the Gouy-Chapman treatment by taking into account dielectric saturation $[25,26]$ and the dependence of the dielectric constant on electrolyte concentration. Several theorists have used statistical mechanical methods to develop treatments applicable to higher concentrations (see eq. (3), [28-30]). Barlow [3] has treated the diffuse layer using cluster theory in a manner analogous to Friedman's treatment of electrolytes [23].

At concentrations of $\sim 1 \mathrm{M}$ and higher, the Debye length $(1 / \kappa)$ approaches the dimensions of the solvated ions and the Gouy-Chapman layer is no longer really diffuse. All of the presently available treatments become questionable. Fortunately in concentrated electrolytes, the fraction of the potential drop across this layer becomes a small fraction of the total drop across the interface, and hence the potential drop across the diffuse layer no longer has much effect on specific ionic adsorption, the kinetics of electrode reactions or the capacitance of the interface.

2.2 THE COMPACT DOUBLE LAYER. - Much attention has been focused by electrochemists on the compact double layer because of its importance to the understanding of electrochemical kinetics. The most widely accepted model is that shown in figure 2 as proposed by Bockris, Devanathan and Müller [22] for a negatively charged electrode in an electrolyte such as $\mathrm{NaCl}$. The cations usually interact much more strongly with the solvent in the inner coordination spher than do the anions. Consequently the cations are shown to approach in significant numbers onto an outer Helmholtz plane position ( $x_{2}$ in figure $1 b$ ) with essentially two water molecules interposed between them and the electrode. The energy for anion adsorption with the exception of fluoride anions is much lower and hence they are able relatively easily to approach directly to the electrode surface. Thus specific adsorption occurs with the orbitals of the anions interacting directly with orbitals of the metal. If the chemical interaction is sufficiently strong, the anions will be specifically adsorbed even if the metal is negatively charged, as in figure 2 . A similar situation can occur for cations but the interaction with the electrode must be usually stronger than with most anions in order to offset the larger solvation energy. Figure 3 indicates the potential energy-distance relation corresponding to cations and anions in figure 2. The potential of zero charge is shifted by specific ionic adsorption (the Esin-Markov effect [30]).

Various chemical physicists and electrochemists

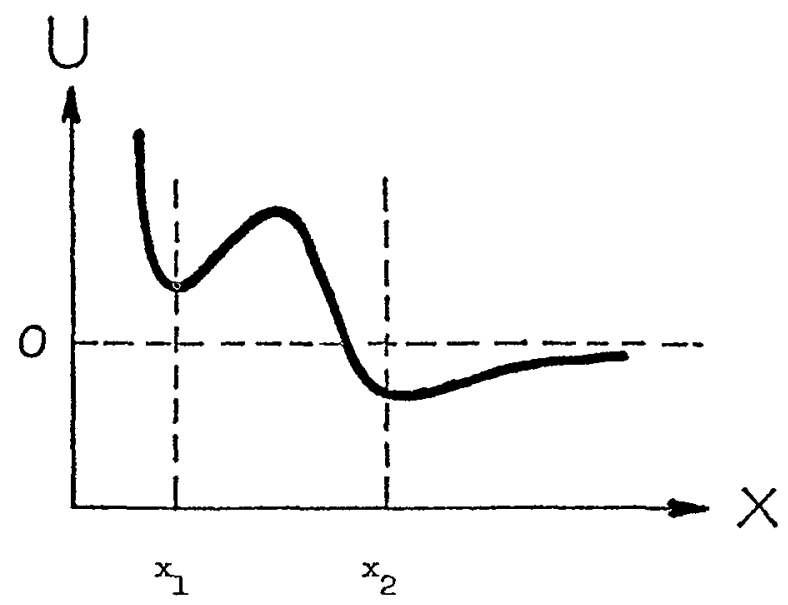

a. without specific ionic adsorption

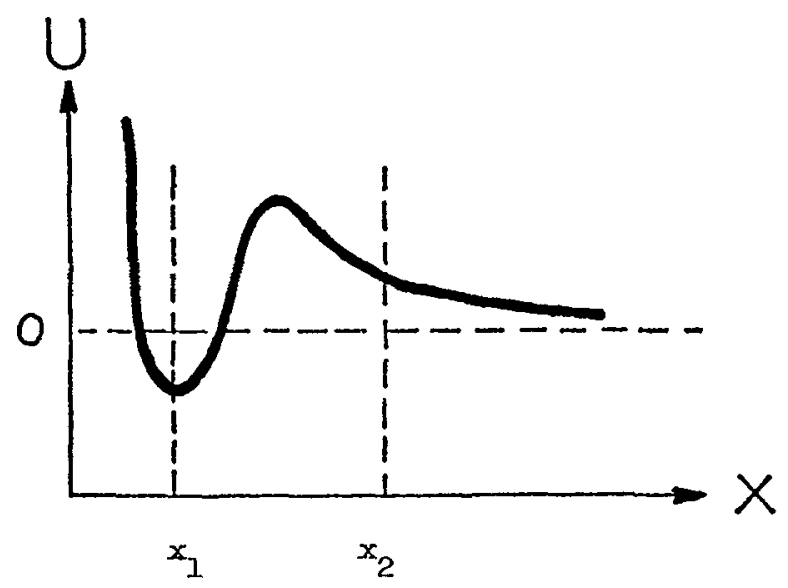

b. with specific ionic adsorption

FIG. 3. - Potential energy versus distance for anions and cations corresponding to figure 2 .

have attempted to develop a theoretical description of the compact double layer both with and without specific ionic adsorption. The test for these treatments has generally been their ability to account for the differential capacitance of the $\mathrm{Hg}$ interface as functions of charge or potential and electrolyte concentration. The diffuse and compact double layer contributions to the overall differential capacitance of the interface are generally represented by two capacitances in series. Thus

$$
\frac{1}{C}=\frac{1}{C_{m-2}}+\frac{1}{C_{2-s}} .
$$

The diffuse layer component $C_{m-2}$ can be evaluated from eqs. (3), (3a), (3b) and for a symmetrical electrolyte is

$$
C_{2-s}=\left(\frac{z^{2} e^{2} \varepsilon c}{2 \pi k T}\right)^{1 / 2} \cosh \left(\frac{z e \varphi_{2}}{2 k T}\right) .
$$

This equation indicates that the diffuse layer contribution gœs through a minimum at $\varphi_{2}=0$ and hence at $E=E_{\mathrm{pzc}}$. Further, $C_{2-s}$ is very large compared to the 
experimentally observed $C$ except in dilute solutions and even then except at potentials close to $E_{\mathrm{pzc}}$. This then facilitates the evaluation of the compact layer capacitance $C_{m-2}$ since in solutions of $\geqslant 0.1 \mathrm{M}$, $C_{m-2} \cong C$ to a good approximation even at $E_{\mathrm{pzc}}$ and furthermore in dilute solutions it is possible to calculate $C_{2-s}$ reasonably reliably (see Fig. 4).

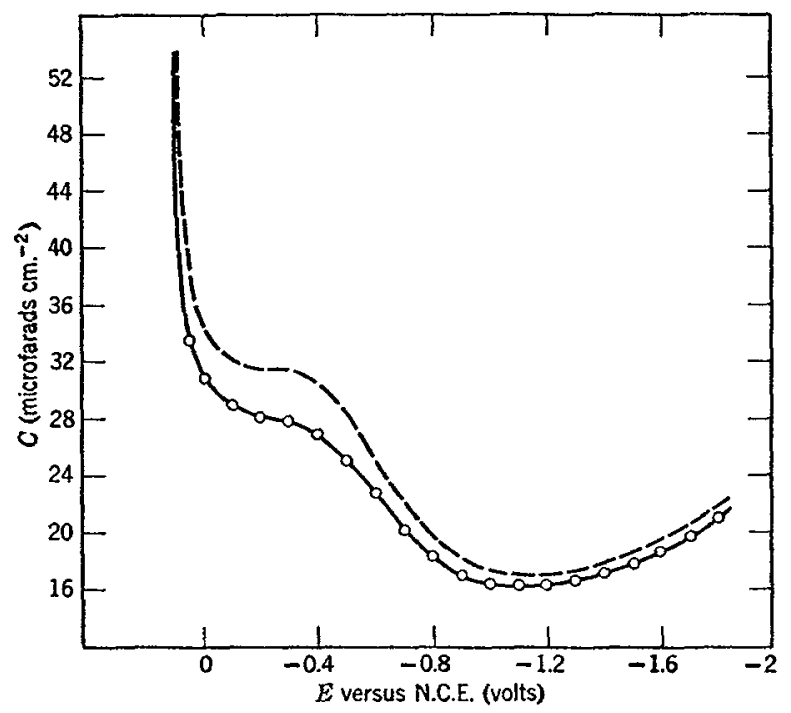

Fig. 4. - Differential capacitance versus potential for $\mathrm{Hg}$ in $0.916 \mathrm{M} \mathrm{NaF}$ at $25^{\circ} \mathrm{C}$. Points : experimental. Dashed line : compact layer component after correction for diffuse layer contribution [Grahame [33]].

In general the comparison of theory and experiment in terms of $C_{m-2}$ and its potential dependence has not been impressive. The hump in the curve at potentials positive to $E_{\mathrm{pzc}}$ (Fig. 4) has been a rather critical test of the various models, one that most treatments have not satisfactorially met. Special note is taken of the intriguing treatment of Buff and Slillinger [30] who use the cluster methods of statistical mechanics. Unfortunately they assume that the interactions introduce only a small perturbation in the behaviour of particles whose motion is otherwise uncoupled, independent and random.

Many treatments of the compact double layer involve two-state models for water [e. g. 22, 24, 26, 34-36] where the two states may correspond to orientation of the water dipole toward or away from the surface as shown in figure 2. Recently Damaskin and Frumkin [37] have proposed a model (without specific ionic adsorption) in which the water at the interface of the $\mathrm{Hg}$ electrode exists in small clusters with chemisorption of individual water molecules occurring at more positive electrode potentials. The clusters are assumed to have a small dipole moment which can be oriented either toward or away from the surface. Parsons [39] and Damashen [38] have refined the treatment of this model and obtain reasonably good fits to the experimental capacitance vs. charge data, even considering the several somewhat adjustable parameters. Damaskin used Boltzmann statistics to calculate the surface concentration of the cluster, assuming that the clusters consist of a fixed number of water molecules $(n)$ and have their dipole moments oriented toward $\left(N \uparrow_{\mathrm{c}}\right)$ or away $\left(N \downarrow_{\mathrm{c}}\right)$ from the electrode surface. Thus if $N_{\mathrm{T}}$ is the total number of entities on the surface, then

$$
N_{\mathrm{T}}=N \uparrow_{\mathrm{c}}+N \downarrow_{\mathrm{c}}+N_{\mathrm{ad}}
$$

where

$$
\begin{aligned}
& N \uparrow_{\mathrm{c}} / N_{\mathrm{T}}=\left(1 / f_{0}\right) \exp \left(\mu_{\mathrm{c}} \uparrow X / k T\right) \\
& N \downarrow_{\mathrm{c}} / N_{\mathrm{T}}=\left(1 / f_{0}\right) \exp \left(-\mu_{\mathrm{c}} \downarrow X / k T\right) \\
& N_{\mathrm{ad}} / N_{\mathrm{T}}=\left(1 / f_{0}\right) \exp \left[\left(-U+\mu_{\mathrm{ad}} X\right) / k T\right]
\end{aligned}
$$

with the function $f_{0}$

$$
\begin{aligned}
f_{0}=\exp \left(\mu_{\mathrm{c}} \uparrow X / k T\right) & +\exp \left(-\mu_{\mathrm{c}} \downarrow X / k T\right)+ \\
& +\exp \left[\left(-U+\mu_{\mathrm{ad}} X\right) / k T\right]
\end{aligned}
$$

and $N_{\text {ad }}$ corresponds to the chemisorbed water molecules with the dipole moment $\mu_{\mathrm{ad}}$ and specific absorption energy $U$ at zero field $X$. Damaskin assigns an area to each of these three species and imposes a conservation of surface area condition. The potential drop across the compact layer $\varphi=\varphi_{\mathrm{m}}-\varphi_{2}$ is then assumed to be

$$
\Delta \varphi=\Delta \Psi+\Delta \chi
$$

where the outer potential contribution $\Delta \Psi$ is given by

$$
\Delta \Psi=\frac{4 \pi x_{2}}{\varepsilon} q
$$

and the surface potential contribution is

$$
\Delta \chi=\frac{-4 \pi}{\varepsilon} \sum N_{i} \mu_{i}
$$

and $i$ corresponds to the two orientations of the water clusters and the chemisorbed water; $q$ is the electrode charge. Damaskin takes into account the discreteness of the charge by introduction of a coefficient $\lambda$ which is intended to take into account the action of the field of all other dipoles on the particular dipole under consideration. Thus

$$
X=\frac{4 \pi q}{\varepsilon}+\lambda \frac{\Delta \chi}{x_{2}}=\frac{\Delta \varphi}{x_{2}} .
$$

Differentiation of $\Delta \varphi$ with respect to charge then leads to an expression for the capacitance contribution of the compact double layer as a function of several parameters including the dipole moments of the water clusters and chemisorbed waters, the thickness $x_{2}$, the discreteness factor $\lambda$ and the number of water molecules per cluster. Figure 5 compares the theoretical and experimental values of $C v s . q$ with a reasonable choice of these parameters and their temperature dependence and with $\lambda$ taken as unity. Damaskin concludes from such comparisons that the number of water molecules per cluster is $\sim 3$ at $0^{\circ} \mathrm{C}$ and $\sim 2$ at $85^{\circ} \mathrm{C}$ and also that the dipole moment of the chemisorbed water is much larger $\left(\mu_{\mathrm{ad}}=3.68 \mathrm{D}\right)$ than the usual 


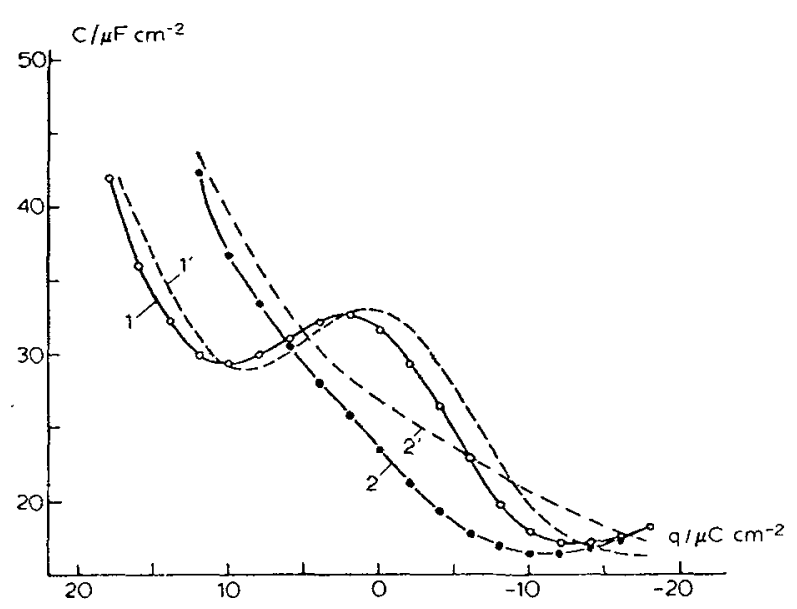

Frg. 5. - Compact layer capacitance versus charge according to Damaskin [38]. Solid lines and points correspond to experimental data of Grahame [40] for $\mathbf{H g}$ in aqueous NaF. Dashed line corresponds to theoretical Curves $1,1^{\prime}: 0^{\circ} \mathrm{C}$. Curves 2, $2^{\prime}: 85^{\circ} \mathrm{C}$. Consult ref. 38 for various parameters used in calculating the theoretical curves $\left(n_{0}=3, n_{85}=2, \lambda=1\right)$ [Damaskin [38]].

value $\left(\mu_{\mathrm{H}_{2} \mathrm{O}}=1.84 \mathrm{D}\right)$. The increment in the compact layer separations at more positive charge density is caused by water chemisorption according to this model. The temperature dependence shown in figure 6 duplicates the major features of the $C v s . q$ experimental data, including the temperature invariant point at $5 \mu \mathrm{C} / \mathrm{cm}^{2}$.

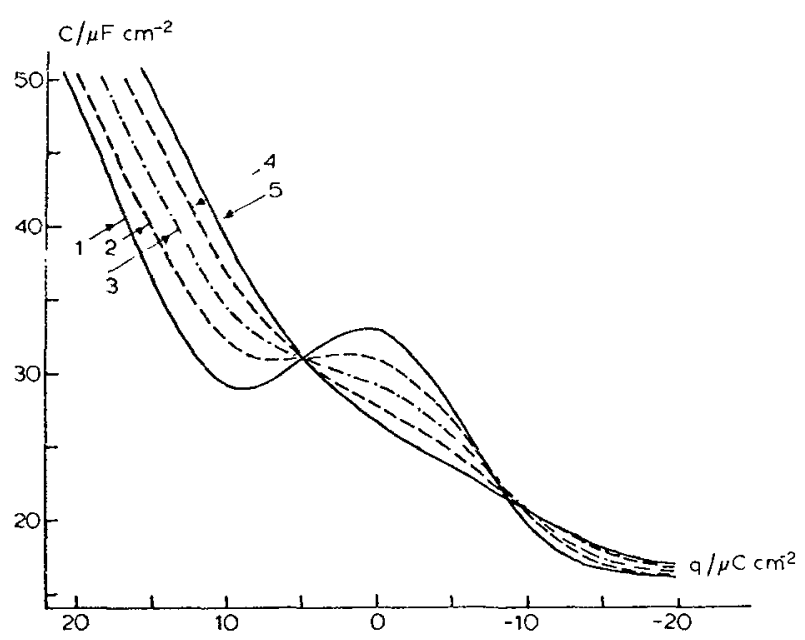

FIG. 6. - Compact layer capacitance versus charge density at various temperatures as calculated by Damaskin [38]. Temperatures : 1) $0{ }^{\circ} \mathrm{C}$, 2) $25^{\circ} \mathrm{C}$, 3) $45^{\circ} \mathrm{C}$, 4) $65^{\circ} \mathrm{C}$, 5) $85^{\circ} \mathrm{C}$. Various parameters are the same as for figure 5 [Damaskin [38]].

Similar theoretical results have been obtained by Parsons [39], who has extended the Damaskin-Frumkin model to four states : individual solvent molecules with their dipole moments perpendicular to the surface and toward or away from the metal ; and clusters also with their net dipole moments towards or away from the metal. Parsons concludes that the most probable size of the clusters at room temperature is 3 or 4 with the total dipole of the cluster equal to approximately that for a single molecule. Parsons points out that small ring clusters of water molecules have some stability on the basis of the theoretical considerations of Del Bene and Pople [41]. On the basis of the three-molecule model of these workers, Parsons concludes that this cluster should have the three O's in a plane parallel to the electrode surface with the out of plane OH's oriented at $62^{\circ}$ relative to this plane. The surface area of each such cluster should be $20 \AA^{2}$.

Despite some degree of agreement between the Damaskin-Frumkin model and experiment, the source of the hump in the $C$ vs. $E$ curves and the high $C$ values at anodic potentials is far from settled. Using a two-state model with individual water dipoles oriented towards or away from the surface, Bockris and Habib [43] have concluded that the solvent cannot be the source of the capacitance hump. Cooper and Harrison have also used a similar two-state model [47]. More recently, Bockris and Habib [46] have extended their treatment to a three-state model by including a dimermonomer equilibrium on the surface. Even with this model they still concluded that the capacitance hump is not the result of a solvent effect.

Several groups including Harrison et al. [44], Bockris and Habib [43, 46] and Reeves [45] have used the experimentally determined temperature dependence of the compact layer capacitance to show that the solvent surface excess entropy passes through a maximum at potentials or charge slightly negative to the pzc (i. e., at a surface charge density of -4 to $-6 \mu / \mathrm{cm}^{2}$ [44]). This is in a region where there are no special features to the capacitance $v$ s. charge density or potential plots. One could normally expect the maximum solvent polarizability to occur when the solvent at the interface has the maximum randomness and hence maximum entropy. This condition would in turn correspond to the maximum or hump in the capacitance vs. charge curves. Failure for this to be the situation is cited as strong evidence against solvent effects as responsible for the hump on the positive side of the pzc [43-46].

On the other hand, the Damaskin treatment [38] dos yield a maximum in the $\partial(1 / C) / \partial T$ vs. charge plot at small negative charge densities, rather close to that observed experimentally for $\mathrm{Hg}$ in aqueous $\mathrm{NaF}$ (see Fig. 7). Since the surface excess entropy of the solvent is calculated from $\partial(1 / C) / \partial T$ as a function of charge density, it is expected that the Damaskin treatment should also lead to the observed maximum in the entropy at small negative charge densities $\left({ }^{2}\right)$.

(2) Damaskin [38] points out, however, that a theory which accounts for the charge dependence of the surface excess entropy may not necessarily account for the temperature dependence of the compact layer capacitance. For example, the Bockris-Habib two-state model dos describe reasonably well the surface excess entropy-charge density curves for $\mathrm{Hg}$ in aqueous $\mathrm{NaF}$ but at the same time predicts a negligible contribution of the solvent to the compact layer capacitance, and hence cannot describe $C v s . T$. 


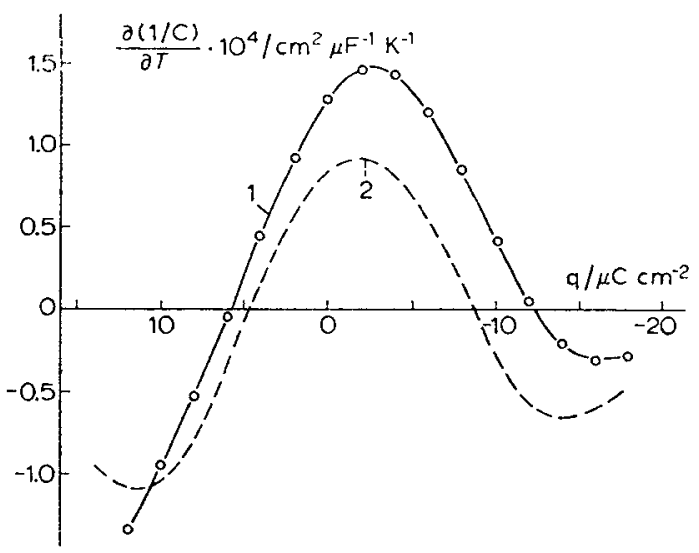

FTG. 7. - Dependence of $\mathrm{d}(1 / C) / \mathrm{d} T$ on charge density. Curve 1 : calculated from Grahame's experimental data [40] for $\mathrm{Hg}$ in aqueous NaF. Curve 2 : calculated from theoretical curves in figure 6 [Damaskin [38]].

A distinct feature of the Damaskin-Frumkin and Parsons treatments is that they provide for changes in the surface concentration of water as well as orientational effects. These both contribute to the surface excess entropy and also the compact layer capacitance. The Brockris-Habib two- and three-state models are such that only orientational contributions are included.

Those workers who are opposed to solvent effects as the explanation for the features of the $C-q$ curves on the positive side of the $p z c$ propose specific anionic adsorption as the cause (see e. g. [42-46]), even with electrolytes involving $\mathrm{F}^{-}$anions. With other anions such as $\mathrm{Cl}^{-}, \mathrm{Br}^{-}, \mathrm{I}^{-}, \mathrm{SO}_{4}^{-}, \mathrm{ClO}_{4}^{-}$there is little question that specific adsorption dos occur with the anion perturbing the compact layer. The $\mathrm{F}^{-}$anion, however, has been presumed to be sufficiently strongly solvated that specific adsorption effects should be minor and probably negligible, at least until very anodic potentials relating to $E_{\mathrm{pzc}}$ are reached. Watts-Tobin [35] suggested that $\mathrm{OH}^{-}$adsorption may occur at anodic potentials. In support of such specific anion effects, is the observation that additions of $\mathrm{HF}_{2}^{-}$anions to a $\mathrm{KF}$ electrolyte produce substantial changes in the shape and position of the hump [48] (see Fig. 8). Various workers have attempted to correct the compact layer capacitance for specific anion adsorption (see e.g. $[49,50])$ but it is not clear that the corrections are valid.

Capacitance measurements for $\mathrm{Hg}$ in various organic solvents show humps or maxima on the anodic side or cathodic side of the pzc or both [57]. In some instances there is little doubt that the hump is the result of specific ionic adsorption because of the strong dependence on the type of anion. In other instances, specific anion adsorption is not a likely explanation.

It is quite evident that electrochemical methods alone are not able to resolve the question of the structure of the water layer adjacent to the metal electrode. The vibrational spectrum of this layer could be of

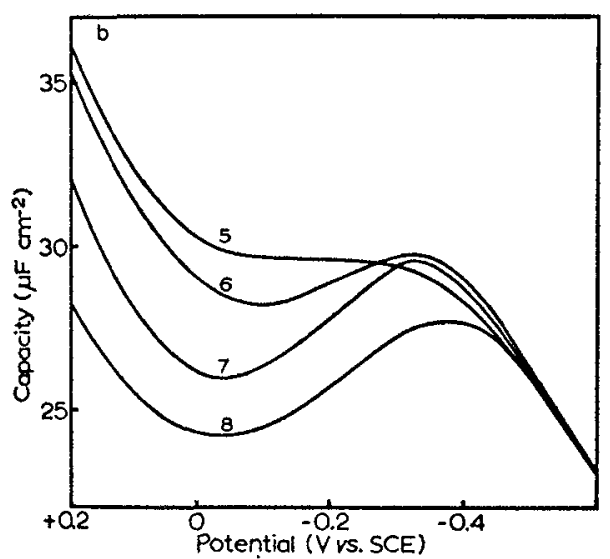

Fig. 8. - Differential capacitance curves in $\mathrm{Hg}$ in $x \mathrm{M}$ $\mathrm{KF}+(1-x) \mathrm{M} \mathrm{KHF}_{2}$. Values $\left.x: 5\right) 0.94$; 6) 0.68 ; 7) 0.35 ; 8) 0.14 [Verkroost et al. [48]].

immense help but neither infrared or Raman are promising because of the problem of distinguishing the properties of a monolayer of water in a sea of bulk water. Efforts have been made by Bewick and Robinson [52] to obtain the optical constants of the water in the compact layer on lead and mercury using UV-visible reflectance spectroscopy but questions exist concerning their method for extracting information concerning the water layer from the reflectance data.

In the discussion so far, the electrode surface has been treated as a well-defined plane and the electronic properties of the electrode properties of the electrode plane not considered. The electronic properties of the electrode phase will be addressed by other speakers in conjunction with the interpretation of the optical properties. Even so, a qualitative description is desirable at this point to complete the discussion of the compact layer.

The truncation of the conduction band orbitals at the electrode surface results in an evanescent wave extending into the interface. When the charge on the metal $q_{\mathrm{m}}$ is changed, the extent to which the evanescent wave extends out from the metal surface changes, as shown in figure 9. The water dipoles and any ionic

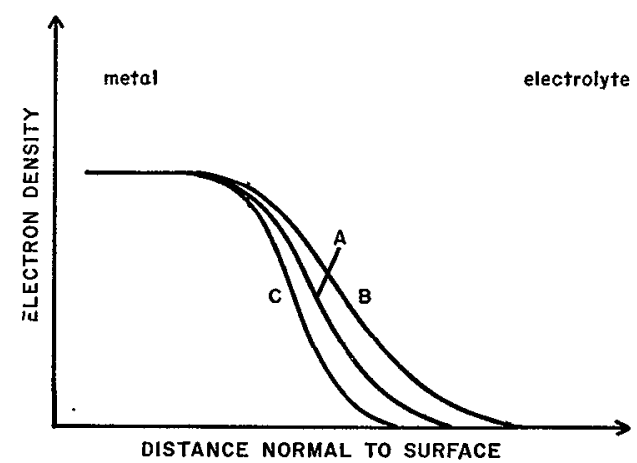

FIG. 9. - Electron density versus distance at a metal electrode surface. Curve A : at potential of zero charge (pzc). Curve B : cathodic to pzc. Curve $\mathrm{C}$ : anodic to pzc. 
species in the inner Helmholtz plane feel this tail of this electron density decay curve. Even if there is no strong localized orbital interactions, their distance of approach will be influenced and the potential distribution across the compact double layer changed. Further, at high positive charge the extension of the evanescent wave out from the surface will be depressed. Under this circunstance, the s-conduction band electrons may no longer be as effective in shielding the more tightly bound $d$ orbitals at the surface and specific interactions between the solvent and the $d$ orbitals of the metal may become more probable. It is hoped that information concerning such interactions will be forthcoming from optical studies but so far, the electroreflectance data have yielded little new insight.

3. Adsorption at electrochemical interfaces. 3.1 General FeAtures. - With solid electrodes and probably even with liquid metals such as $\mathrm{Hg}$, the understanding of the compact layer requires information concerning the possible adsorption sites for water and anionic species. With species that are strongly adsorbed and only weakly interact with other solutions phase species, it may be possible to gain insight into the most likely adorrption sites from theoretical and experimental studies of adsorption at single crystal solid-gas interfaces. Many theorists are involved in efforts to calculate the heats of adsorption of hydrogen, oxygen, water, carbon monoxide and other species on various sites on metal surfaces using a variety of methods including LCAO, extended Hückel molecular orbital theory and $\mathrm{X} \alpha$ scattering. Leban and Hubbard [53] appear to be the first electrochemists to attempt to calculate such information for species of special interest to the understanding of the compact layer. Using the iterative extended Hückel molecular orbital technique, they have arrived at the preferred sites shown in figure 10 for various species on the Pt (III)
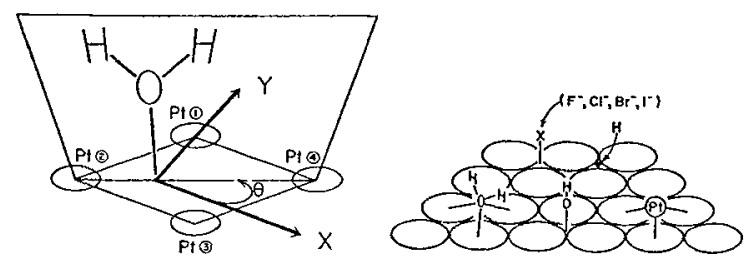

Fra. 10. - Adsorption sites on Pt (111) for various species of the compact layer calculated by the interative extended Hückel molecular orbital method [Leban and Hubbard [53]].

surface. Aside from the limitations of the IEHMO technique, the calculation has other questionable features. Specific interactions of the adsorbed species with solution phase components are not considered some are strong. Further, only five Pt atoms of the metal phase are included in the treatment (see Fig. 11). Even so, this calculation represents a first step for electrochemists.

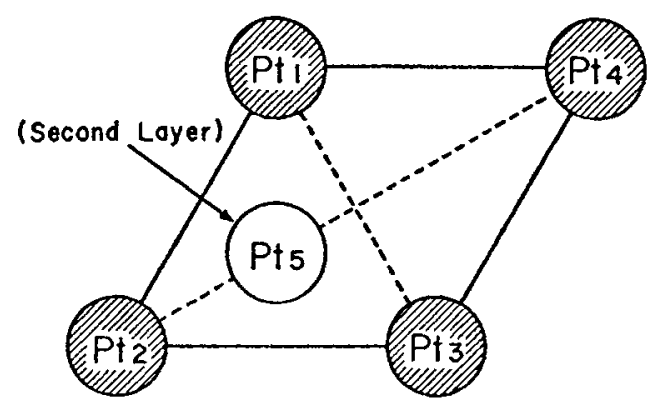

Fig. 11. - Model of Pt (111) surface used by Leban and Hubbard in the IEHMO treatment of adsorbed species. Shaded circles : atoms in the surface layer. Open circle: an atom in the second layer.

With solid electrodes, the potential of zero charge and the double layer capacitance should be dependent on the surface orientation. Ample evidence exists for such dependence in the literature for metals (see e. q. [54-60]) as well as graphite [61, 62]. In general the potential of zero charge appears to be most positive on the plane with the highest atom density for fcc metals such as Ag and Au.

3.2 HYDRogen ELECTROSORPTION. - Electrosorption plays a key role in electrocatatysis, a subject which has taken on new significance because of the world-wide energy problems. The adsorption of hydrogen is among the most important because of its involvement as an intermediates in a number of electrochemical processes. By far the most studied metal surface for hydrogen adsorption is platinum. Linear sweep voltammetry indicates a number of peaks (Fig. 12), whose potential and height are strongly dependent on the type of electrolyte. Conway et al. [64] have observed up to five peaks in sulfuric acid. Various explanations have been proposed including different adsorption sites on a given single crystal surface, a distribution of crystallographic surfaces, induced heterogeneity associated with hydrogen adsorption itself [64] and anion adsorption which induces heterogeneity by clocking sites to varying degrees and perturbing adjacent sites [63]. The pronounced dependence of the hydrogen electrosorption on the type and concentration of anion (Fig. 12) indicates that hydrogen adsorptiondesorption are coupled to anion desorption-adsorption [63].

In an attempt to resolve this problem, various electrochemists have examined hydrogen electrosorption on single crystal Pt. Will [65] examined the low index planes (100), (110) and (111) and found the same two major peaks on these three orientations although the relative heights depended on the crystal orientation. The single crystal Pt electrodes studied by Will probably did not expose a single crystallographic surface. The distribution of crystallographic surface planes depends on the overall orientation and the extent to which the surface has been cycled to anodic potentials. 


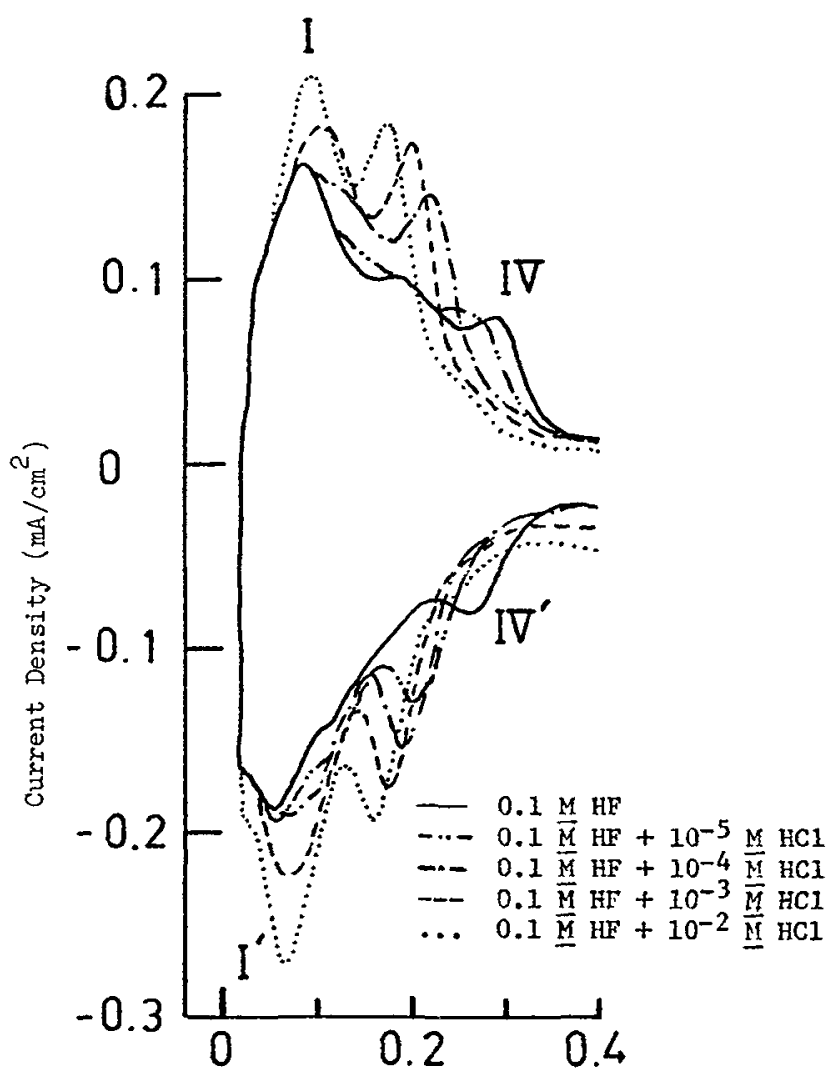

POTENTIAL（V) vs RHE

FIg, 12. - Voltammograms for hydrogen adsorption-desorption on polycrystalline $\mathrm{Pt}$ in $0.1 \mathrm{M} \mathrm{HF}$ with various $\mathrm{HCl}$ additions [Huang, O'Grady and Yeager [63]].

Will arrived at the conclusion that the strongly adsorbed hydrogen peak IV (Fig. 12) corresponds to the (100) plane and the weakly adsorbed peak I to the (110) plane. Rather analogous results have been reported by Bronel et al. [66] for the Pt (100) and (111) surfaces. These workers used electron microscopy to establish that the surfaces were facet-free. Kinoshita and Stonehart [67] have examined hydrogen adsorption on dispersed $\mathrm{Pt}$ as a function of crystallite size and find a dependence which they interpret as further evidence that the multiple peaks result from different surface crystallographic structures.

In contrast, Bagotzky et al. [68] and Conway et al. [64] have concluded from their single crystal Pt studies that there is little difference in the hydrogen adsorption on the (100) (110) and (111) planes. Conway et al. [64] attribute the multiple peaks principally to induced heterogeneity arising from collective longrange electronic interactions.

The probability is high in all of the single crystal studies just cited that the surface prevailing during the electrochemical measurements dos not correspond to a single crystal plane. Even if the Pt crystal has only one plane predominant before the electrosorption measurement, these authors generally cycled their electrodes to anodic potentials in the anodic film region to oxidize or desorb interfering surface contaminants and this procedure is likely to cause restructuring.

Recently several groups have attempted to devise techniques which permit the introduction of a single crystal surface of predominantly one plane and free of impurities into an electrochemical environment with a minimum possibility of restructuring and contamination. These include A. Hubbard at the University of California at Santa Barbara [16, 18], J. A. Jœbstl at Fort Belvoir [19], P. N. Ross at United Technology [20] and the author's group at Case Western Reserve University [17, 21]. Each group has turned its attention to the (100), (110) and (111) planes of Pt and first establishes that the surface is predominantly one plane using low energy electron diffraction (LEED) and free of surface impurities down to a few percent of a monolayer using Auger electron spectroscopy.

The key features of the techniques used by the author's group [75] are vacuum transfer with $99.9999 \%$ argon admitted to the vaccum systems just prior to the electrochemical measurements ; thin-layer electrochemical cell techniques to avoid contamination; and introduction of the $\mathrm{Pt}$ single crystal surfaces into the electrolyte at controlled potentials in the hydrogen adsorption region. In the cyclic voltammetry studies of hydrogen electrosorption, the potential range is restricted to +0.05 to $0.40 \mathrm{~V}$ vs. RHE to reduce any possible restructuring. The voltammetry curves on the single crystal Pt surfaces retract with repeated cycling, starting with the very first sweep. If the voltage sweep is extended into the anodic film formation region to $\geqslant 1.4 \mathrm{~V}$ vs. RHE, the hydrogen adsorption region changes significantly with new peaks appearing or very minor peaks becoming major peaks, depending on the original surface. This is probably the result of restructuring although the possibility exists that oxygen has been irreversibly adsorbed into sites within the surface layer.

On the Pt (100) surface, Hubbard et al. [18], Ross [20] and our group [21] find one predominant peak (Fig. 13) corresponding to the strongly adsorbed hydrogen peak on polycrystalline $\mathrm{Pt}$ in acid solutions. The LEED pattern for the Pt (100) indicates a $5 \times 1$ overlayer mesh $[15,21]$. This surface probably reverts to $(1 \times 1)$ in contact with the electrolyte. On the $\mathrm{Pt}$ (111) surface, our group finds only a minor peak corresponding to weakly adsorbed hydrogen while Ross and Hubbard et al. report a major peak. The source of this discrepancy is not fully clear but may be caused by exposure to or cycling of the electrode to potentials in the anodic film region by the other groups. Alternatively our Pt (111) surface might have some of the sites blocked by an impurity but Auger dœs not indicate any such impurity. In any event, the presence of only one major peak on the (100) Pt surface provides strong evidence that the principal peaks on polycrystalline Pt correspond to different crystallographic planes. 


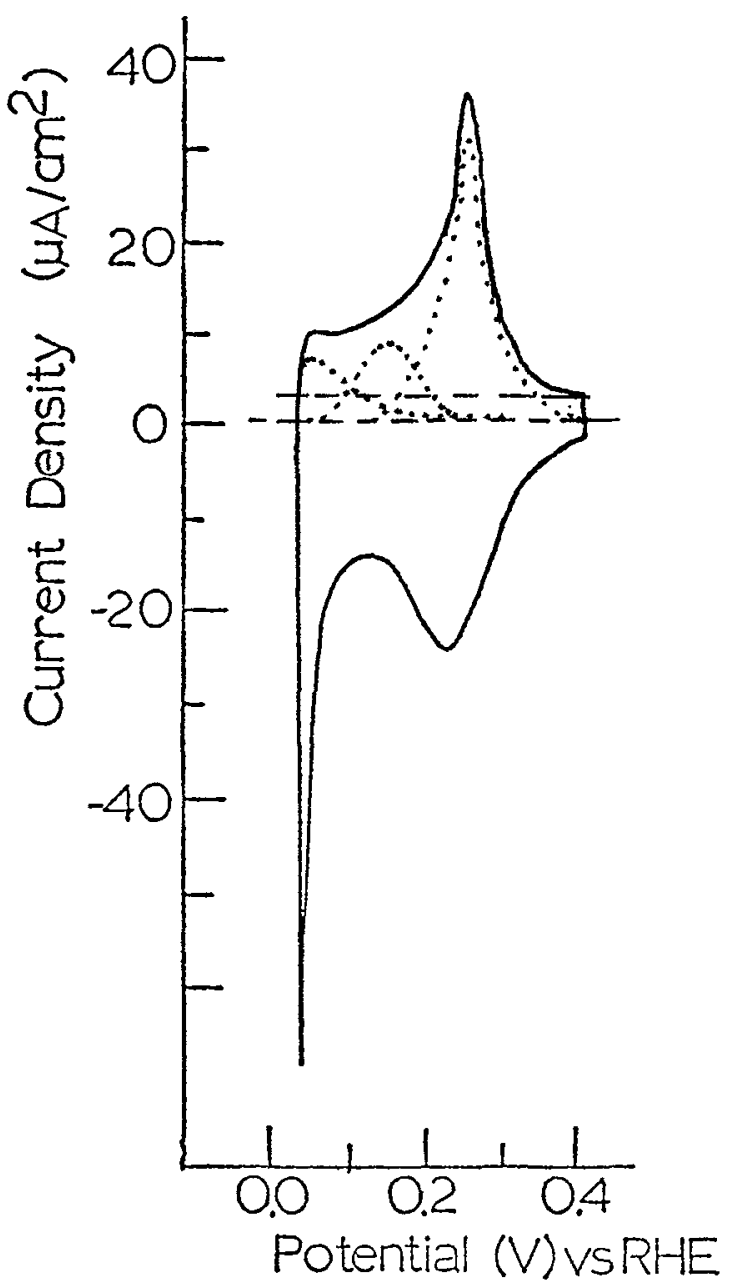

FIG. 13. - Voltammogram for hydrogen adsorption-desorption on clean $\mathrm{Pt}(100-5 \times 1)$ in $0.05 \mathrm{M} \mathrm{H}_{2} \mathrm{SO}_{4}$. Sweep rate: $50 \mathrm{mV} / \mathrm{s}$ [O'Grady, Woo, Hagans and Yeager [211].

Hydrogen adsorption has been studied on polycrystalline Pt electrodes using UV-visible reflectance spectroscopy by McIntyre and Kolb [69] and Bewick and Tuxford [70]. The strongly bound hydrogen (peak IV in figure 12) produces only a small reflectance increase at $435 \mathrm{~nm}$ while the weakly bound component (Peak I) produces a larger reflectivity decrease [70]. The means by which the hydrogen adsorption produces these optical changes have not yet been established. The effect may be caused principally by changes in the surface conductivity rather than by the chemical bonding itself.

3.3 UNDERPOTENTIAL ELECTRODEPOSITION OF OTHER SPECIES. - Various metal cations electrodeposit on foreign metal substrates in mono- and submonolayers at potentials far below the reversible potentials for electrodeposition of the bulk metals. UPD is of considerable interest to electrochemists because of the importance of such layers to the understanding of electroplating [78] as well as the interesting electrocatalytic properties of such layers (e. g. [79, 80]). These layers range from principally ionic to metallic depending on the particular solution phase species, substrate, coverage and potential. This phenomenon resembles somewhat the adsorption of metal atoms from the gas phase on foreign metal substrates (see e. g. [81-85]) except that the solvent (particularly water) at the interface tends to enhance the ionic character of the bonding of the adsorbate to the metal substrate. Field emission studies (e. g. [86-87]) have helped to identify the nature of the electronic interactions for such layers on metals in vacuo. Quantum mechanical models have been developed for the interaction of the valency orbitals of the adsorbed species with the conduction and valence bands of the metal substrate (e. g. [88]). LEED studies have indicated ordering in some such monolayers (e. g. [83]). Unfortunately such information can not be translated to the corresponding electrochemical interface because the interactions with solvent are expected to be strong in many instances. Various electrochemical methods (for a review see ref. [89]) have been used to obtain information concerning coverage and the charge supplied to the electrode but have yielded little atomic level information concerning the absorbate-substrate bonding. Bowles and Cranshaw [90] have obtained in situ Mössbauer data for $\mathrm{Sn}$ on $\mathrm{Pt}$, indicating metallic character for the UPD layer but Mössbauer spectroscopy is quite limited in its applicability. The principal spectroscopic tool has been UV-visible reflectance spectroscopy [76, 91-94], including ellipsometry [77]. The optical data carry quantitative information concerning the surface interactions involved in UPD but the interpretation of such data is still in a very qualitative state [9].

The various features of UPD are well illustrated by $\mathrm{Pb}$ on $\mathrm{Au}$ substrates. Figures 14 and 15 indicate the current-voltage curves for the adsorption and desorption of $\mathrm{Pb}$ species during linear voltage sweeps for vapor deposited polycrystalline and single-crystal $\mathrm{Au}$ substrates. Conway [95] has resolved 7 peaks for the UPD of $\mathrm{Pb}$ on polycrystalline $\mathrm{Au}$. The substrate morphology has a pronounced effect on these voltammetry curves as well as the charge-potential curves (Fig. 16). Similar effects have been reported for other cations on single crystal Au by Schultze and Dickertmann [71]. The peaks in the voltammetry curves are accompanied by relatively large changes in the reflectivity and ellipsometric parameters [77].

The widths of the voltammetry peaks attending the adsorption and desorption of a solution phase species depend on the heterogeneity of the surface and the interactions between adjacent species in the UPD layer and also the water molecules at the interface. Attractive interactions between the adsorbed species cause the peak to narrow down. The sharp peak at $+0.050 \mathrm{~V}$ vs. SHE in figure 14, however, is extremely narrow and has fine structure which is not fully resolved. The effects of sweep rate and electrolyte concentration [83] indicate that this peak dœs not correspond to adsorption-desorption but rather a transi- 


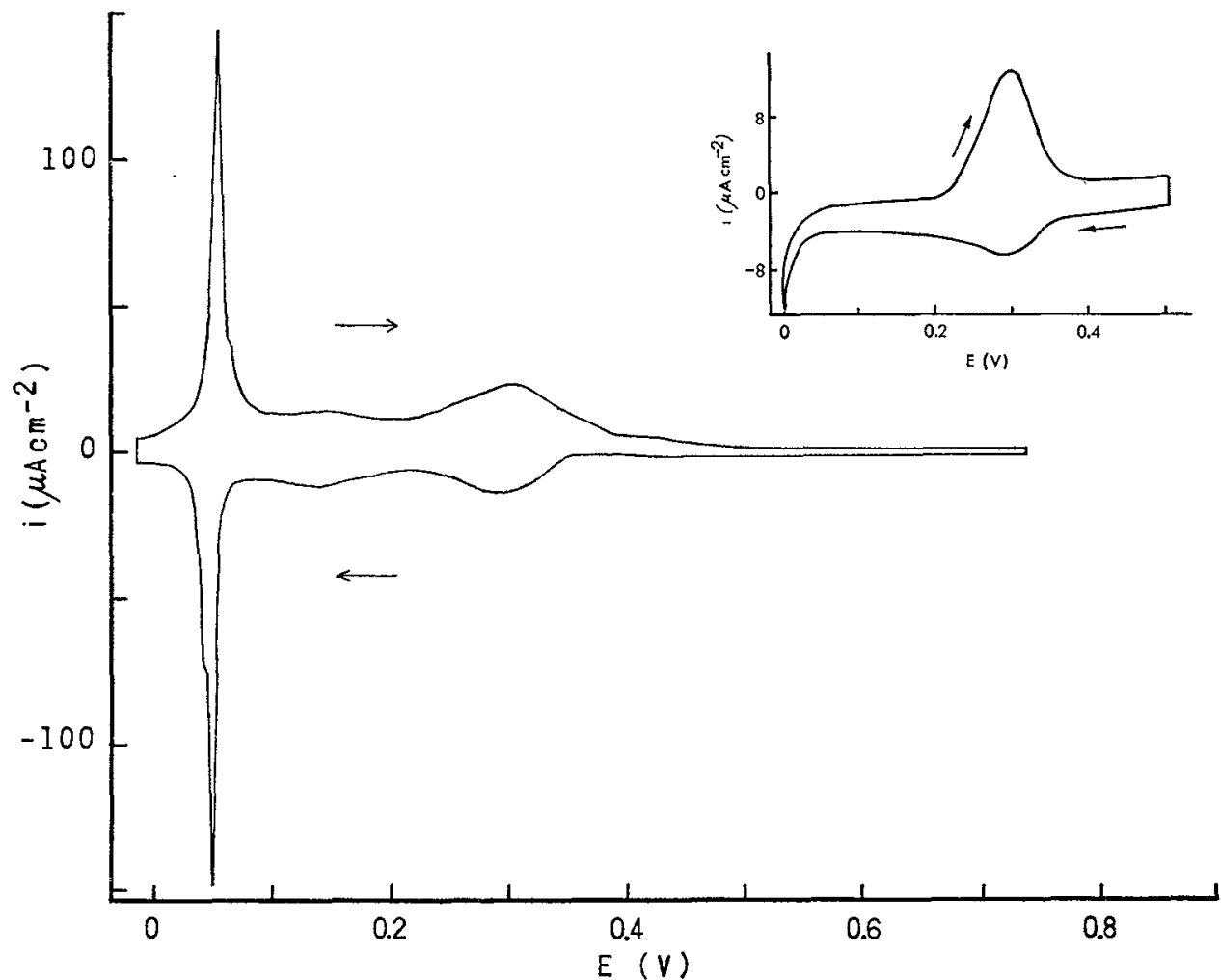

FIG. 14. - Underpotential deposition of $\mathrm{Pb}$ on polycrystalline $\mathrm{Au}$ in $1 \mathrm{mM} \mathrm{Pb}\left(\mathrm{NO}_{3}\right)_{2}+1 \mathrm{M} \mathrm{HClO}_{4}$. Sweep rate : $20 \mathrm{mV} / \mathrm{s}$ : Insert : behavior with $1 \times 10^{-5} \mathrm{M} \mathrm{Pb}{ }^{2+}$ [Adzic, Yeager and Cahan [76]].

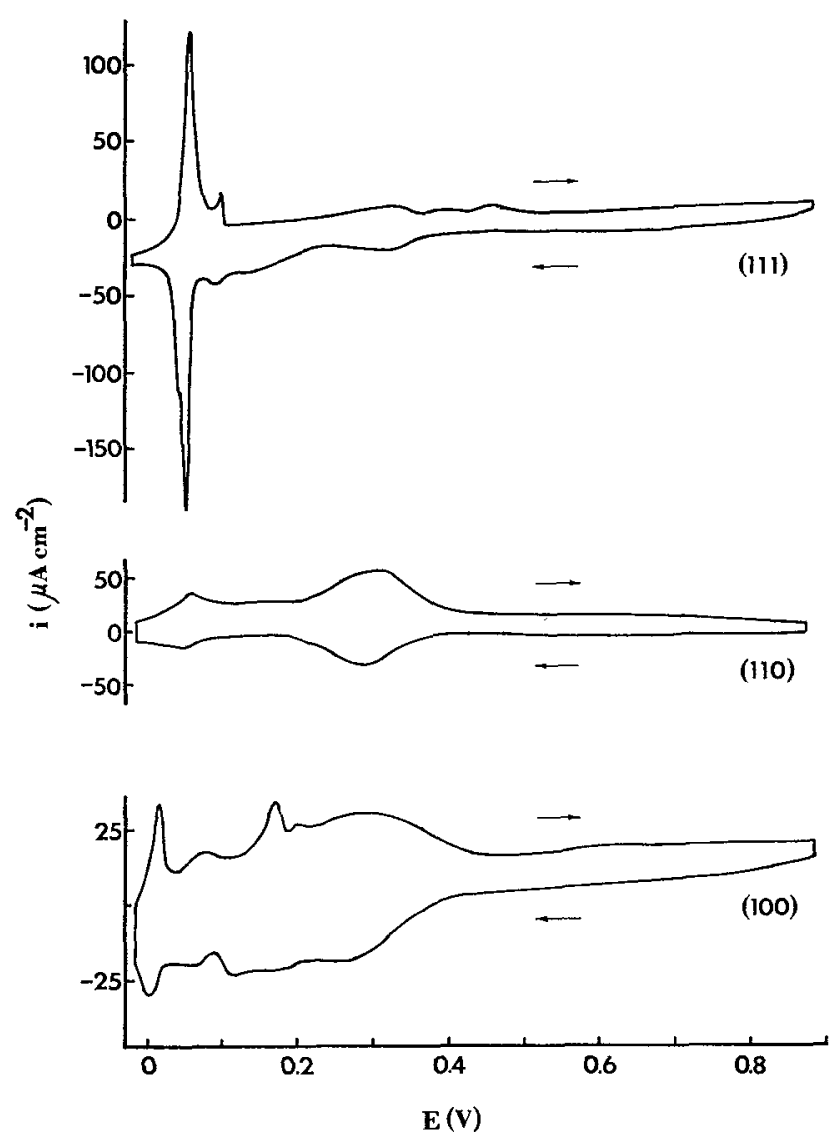

Fig. 15. - Underpotential deposition of $\mathrm{Pb}$ on single crystal $\mathrm{Au}$ in $1 \mathrm{mM} \mathrm{Pb}\left(\mathrm{NO}_{3}\right)_{2}+1 \mathrm{M} \mathrm{HClO}_{4}$. Sweep rate : $20 \mathrm{mV} / \mathrm{s}$ [Adzic, Yeager and Cahan [76]]. tion within the UPD layer involving a change in the surface charge. This change might be an order-disorder transition of the type observed with adsorbed layers at metal-vacuum interfaces. On the other hand, the change in charge attending this peak is large (see Fig. 16),

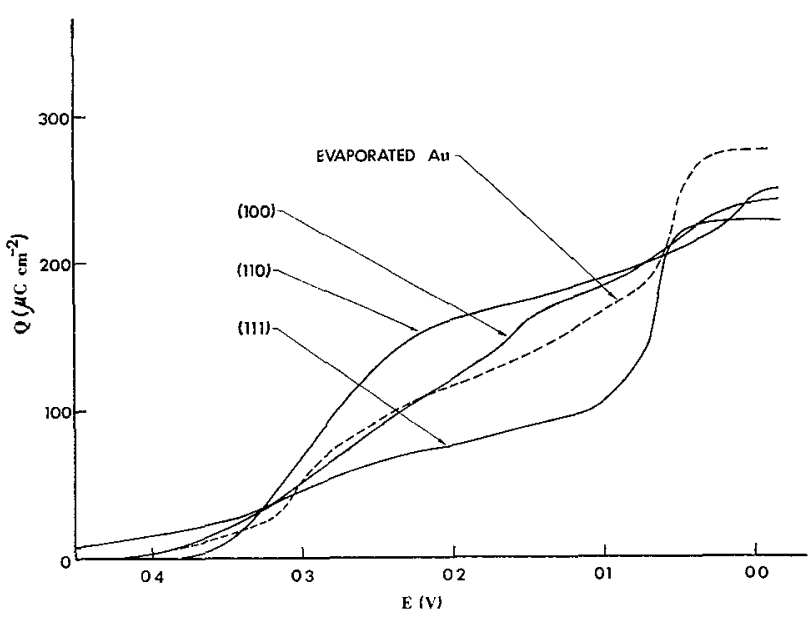

FIG. 16. - Charge density versus potential curves for the UPD of $\mathrm{Pb}$ on single crystal $\mathrm{Au}$, obtained from figure 14. [Adzic, Yeager and Cahan [76]].

and further, the ellipsometric measurements indicate a pronounced change to a more metallic-like layer [84]. It has been proposed [76] that this peak corresponds to a phase transition in which the adsorbed $\mathrm{Pb}$ species with significant ionic character condense into 
metallic patches. The situation may be represented as follows

$$
\begin{aligned}
& \mathrm{Pb}_{\mathrm{aq}}^{2+}+(2-y) \mathrm{e}^{-} \leftrightharpoons \mathrm{Pb}_{\mathrm{ads}}^{y+} \\
& \mathrm{Pb}_{\mathrm{ads}}^{y+}+y \mathrm{e}^{-} \leftrightharpoons \mathrm{Pb}_{\mathrm{ads}}
\end{aligned}
$$

where reaction a corresponds to the more anodic voltammetry peaks and reaction $b$ to the very sharp peak in figure 14. Unfortunately it is not possible to measure directly $y$ in reactions $\mathrm{a}$ and $\mathrm{b}$ since the charge passed through the external circuit includes the charge necessary to compensate changes in the ionic double layer.

A probable model for the interactions of the absorbed $\mathrm{Pb}$ with the $\mathrm{Au}$ substrate and other adsorbed lead ions or atoms is presented in figure $17 \mathrm{~A}$ and $\mathrm{B}$

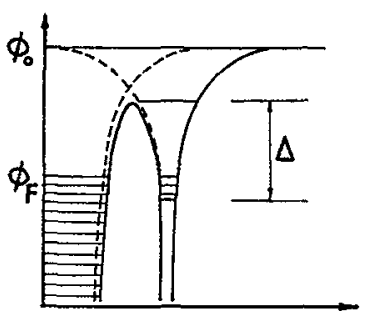

DISTANCE FROM SURFACE

A

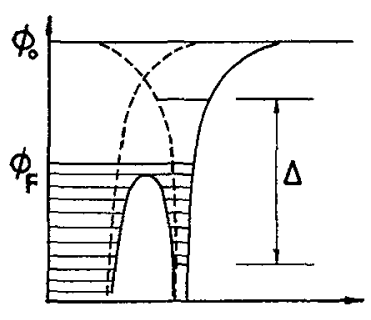

DISTANCE FROM SURFACE

C
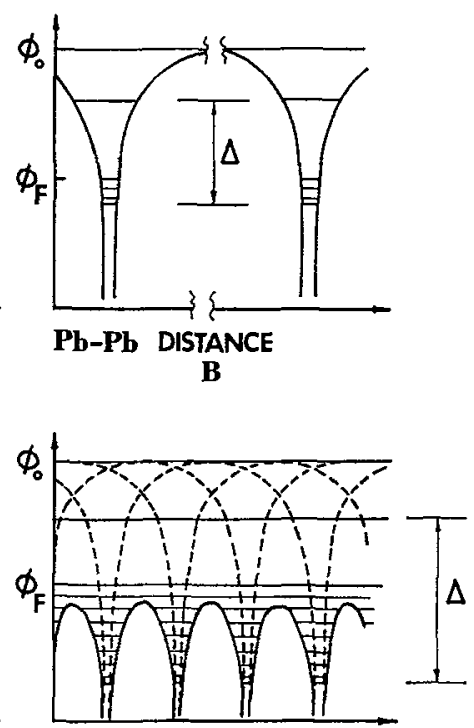

Pb-Pb DISTANCE

D

Fig. 17. - Energy level diagram for lead on gold. A and B, Behavior at low and moderate coverage. $C$ and $D$, Behavior at high coverage. $A$ and $C$, Perpendicular to surface. $B$ and $D$, Parallel to surface. $\varphi$. Potential energy of electron in unbound state ; $\varphi_{\mathrm{F}}$, Fermi energy ; $\Delta$, band width in $\mathrm{Pb}$. Solid curves combined metal substrate-lead potential curves ; dashed lines, parallel curves with no interactions of lead with gold substrate or other adsorbed lead [Adzic, Yeager and Cahan [76]].

for low moderate coverage where the lead is ionic and in figure $17 \mathrm{C}$ and $\mathrm{D}$ for high coverage where the $\mathrm{Pb}$ is metallic. The representation is that usually employed for adsorption at metal-gas interfaces (see e. g. [87]) and makes no attempt to show solvent states. Further, these figures are applicable at or near the point of zero charge (pzc) where the potential gradients associated with differences in the potentials of the metal and solution phases are small compared with those intrinsic to the electronic structure of the interface. Figure $17 \mathrm{~A}$ and $\mathrm{C}$ represent the potential energy profiles perpendicular to the surface through the center of a $\mathrm{Pb}$ ion or atom while figure $17 \mathrm{~B}$ and $\mathrm{D}$ represent the corresponding profiles parallel to the surface through the center of nearest neighbour $\mathrm{Pb}$ ions or atoms. The dashed lines represent the potential energy of an electron when there is no interaction, electrostatic or otherwise, between the $\mathrm{Au}$ and $\mathrm{Pb}$. The solid curves are the combined potential energy curves.

In figure $17 \mathrm{~A}$ and $\mathrm{C}$ the potential energy curve between the metal surface and the $\mathrm{Pb}$ is lowered near the intersection of the two separate curves by resonance splitting. At high coverages, this resonance splitting is much larger than at low coverages because the three-dimensional aspect of $\mathrm{Pb}-\mathrm{Pb}$ as well as $\mathrm{Pb}-\mathrm{Au}$ interactions becomes important.

In figure $17 \mathrm{~A}$ the valence orbitals (6p) of the adsorbed $\mathrm{Pb}$ are broadened through interaction with the orbitals of the $\mathrm{Au}$ with part of the $\mathrm{Pb}$ valence orbital band below the Fermi level. This results in a charge on the adsorbed $\mathrm{Pb}$ of less than +2 . The depression of the potential energy barrier between the $\mathrm{Pb}$ and $\mathrm{Au}$, however, is assumed not to be sufficent to reduce the top of the barrier below the Fermi level and thus in this case, the $\mathrm{Pb}-\mathrm{Au}$ interaction is not yet metalliclike. The possibility that the barrier has been pulled down below the Fermi level, even at low coverages, cannot be ruled out at this time, but this is unlikely without the three-dimensional interactions within the layer as well as between the layer and the substrate.

Such three-dimensional interactions are to be expected at high coverages. In figure $17 \mathrm{C}$ and $\mathrm{D}$, the barriers are shown depressed below the Fermi level, $i$. e., the lead layer is metallic. The phase transition to which the sharp $\mathrm{Pb}$ voltammetry peak is ascribed serves to bring the $\mathrm{Pb}$ species into the close proximity required to achieve metallic properties for the layer.

The potential energy plots in figure 17 will change with electrode potential, at least qualitatively, in a manner similar to that used to represent the situation in field emission at metal-vacuum interfaces [87]. In figure $17 \mathrm{~A}$, the barrier will be lowered as the electrode potential is driven cathodic. Once the barrier falls below the Fermi level, however, the fraction of the electrode potential difference felt by this barrier will become very small because of the metallic properties of the $\mathrm{Pb}$ and the smallness of the Thomas-Fermi screening distance.

4. Conclusion. - This discussion indicates that the electrochemist has very little quantitative understanding of his interfaces and that even his qualitative models are often in doubt. Hopefully in situ optical methods combined with theoretical methods will lead to new insight in to the nature of electrochemical interfaces.

Acknowledgment. - The preparation of this paper has been made possible through research support from the U. S. Office of Naval Research. 


\section{References}

[1] Barlow, C. A., Jr., The Electrical Double Layer, in Physical Chemistry, An Advanced Treatise, Vol. IXA, Chapter 2, H. Eyring, D. Henderson and W. Jost, eds. (Academic Press, New York City) 1970.

[2] Barlow, C. A., Jr. and MacDonald, J. R., Theory of Discreteness of Charge Effects in the Electrolyte Compact Double Layer in Advances in Electrochemistry and Electrochemical Engineering, P. Delahay and C. Tobias, eds. (J. Wiley and Sons, New York) 1967.

[3] Payne, R., J. Electroanal. Chem. 41 (1973) 277.

[4] Lorenz, W., Z. Phys. Chem. 248 (1971) 161 ; 252 (1973) $374 ; 253$ (1973) 243.

[5] VetTer, K. J. and SChultZe, J. W., Ber. Bunsenges. Phys. Chem. 76 (1972) 920.

[6] Schultze, J. W. and Vetter, K. J., J. Electroanal. Chem. 44 (1973) 63 ; 53 (1974) 67; Electrochim. Acta 19 (1974) 230 .

[7] Schultze, J. W. and Koppitz, F. D., Electrochim. Acta 21 (1976) 327.

[8] Frumrin, A., Damaskin, B. and Petrir, O., J. Electroanal. Chem. 53 (1974) 57 ; Elektrokhim. 12 (1976) 1.

[9] MCINTYRE, J. D. E., Optical Techniques in Electrochemistry, Vol. 9, R. H. Muller, ed., Advances in Electrochemistry and Electrochemical Engineering (J. Wiley and Sons, New York City) 1973.

[10] Blondeau, G. and Yeager, E, Prog. Solid State Chem. 11 (1976) 153.

[11] ReEd, A. and Yeager, E., Electrochim. Acta 15 (1970) 1345.

[12] LASER, D. and ARIEL, M., J. Electroanal. Chem. 41 (1973) 381.

[13] (a) Fleischmann, M., Hendra, P. and McQuillan, A. J., Chem. Phys. Lett. 26 (1974) 163.

(b) McQuillan, A. J., Hendra, P. J. and FleischMANN, M., J. Electroanal. Chem. 65 (1975) 933.

(c) CoOnex, R. P., Reid, E. S., Hendra, P. J. and FleischManN, M., J. Am. Chem. Soc. 99 (1977) 2002.

[14] Van Duyne, R. P., Jeanmaire, D. L., Suchanski, M. R., Wallace, W. and CAPE, T., Resonance Raman Spectroelectrochemistry, National Meeting, The Electrochemical Society, Washington, D. C., May 1976 Paper 357 (Extended Abstracts, pp. 883-4).

[15] HAGEN, G. and YeAGER, E., unpublished data for electrosorbed p-nitrosodimethyl aniline; to be submitted for publication.

[16] Ishikawa, R. M. and Hubbard, A. T., J. Electroanal. Chem. 69 (1976) 317.

[17] O'Grady, W. E., Woo, M. Y. C., Hagans, P. L. and Yeager, E., J. Vac. Sci. Technol. 14 (1977) 365.

[18] Hubbard, A. T., Schoeffel, J. A. and Walter, H. W., Ethylene Hydrogenation and Related Reactions on Single Crystal and Polycrystalline Pt Electrodes, National Meeting, American Chemical Society, New Orleans, Mar. 1977, Paper COLL-142.

[19] JoEbstu, J. A., Surface Characterization of Electrocatalysts by LEED, Auger Electron Spectroscopy and Related Techniques, First Chemical Congress of North American Continent, Mexico City, Nov. 30-Dec. 5, 1975. Paper PHSC-18.

[20] Ross, P. N., Electrocatalytic Properties of Single Crystal Pt Surfaces in Aqueous Acid Electrolytes, in Proceedings of the Symposium on Electrode Materials and Processes for Energy Conversion and Storage, National Meeting, The Electrochemical Society, Philadelphia, May 8-13, 1977, Paper 343. (Extended Abstracts, pp. $878-880$ ).
[21] O'Grady, W. E., Wood, M. Y. C., Hagans, P. L. and YEAGER, E., Electrochemical Hydrogen Adsorption on the Pt (111) and (100) Surfaces, loc. cit., Paper 335 (Extended Abstracts, pp. 859-861).

[22] Bockris, J. O'M., Devanathan, M. A. and Muller, K. Proc. R. Soc. A 274 (1963) 55.

[23] Friedman, H. L., Ionic Solution Theory Based on Cluster Expansion Methods (J. Wiley and Sons, New York) 1962.

[24] Мотт, N. F. and Watts-Tobin, R. J., Electrochim. Acta 4 (1961) 79.

[25] Brodowsky, H. and Strehlow, H., Z. Elektrochem. 63 (1959) 262

[26] MacDonald, J. R., J. Chem. Phys. 22 (1954) 1857.

[27] Lippmann, G., Ann. Chim. Phys. 5 (1875) 494.

[28] Krylov, V. S. and Levich, V. G., Zhur. Fiz. Khim. 37 (1963) 2273.

[29] Levich, V. G. and KiR'Yanov, V. A., Dokl. Akad. Nauk. SSR 131 (1960) 1134.

[30] Buff, F. B. and Stillinger, F, H., J. Chem. Phys. 39 (1963) 1911

[31] Esin, O. A. and Markov, B. F., Zhur. Fiz. Khim. 13 (1939) 318.

[32] Grahame, D. C., Z. Elektrochem. 62 (1958) 264.

[33] Grahame, D. C., J. Am. Chem. Soc. 76 (1954) 4819.

[34] Macdonald, J. R. and Barlow, C. A., J. Chem. Phys. 36 (1962) 3062.

[35] Watts-Tobin, R. J., Philos. Mag. 6 (1961) 133

[36] Levine, S., Belt, G. and Smith, A., J. Phys. Chem. 73 (1969) 3534.

[37] Damaskin, B. B. and Frumkin, A. N., Electrochim. Acta 19 (1974) 173.

[38] Damaskin, B. B., J. Electroanal. Chem. 75 (1977) 359.

[39] Parsons, R., ibid. 59 (1975) 229.

[40] Grahame, D. C., J. Am. Chem. Soc. 79 (1957) 2093.

[41] Del Bene, J. and Pople, J. A., J. Chem. Phys. 52 (1970) 4858.

[42] Payne, R., J. Electroanal. Chem. 41 (1973) 309.

[43] Bockris, J. O'M. and HABID, M. A., ibid. 65 (1975) 473.

[44] Harrison, J A., Randles, J. E. B. and Scheffrin, D. J., ibid. 48 (1973) 359.

[45] Rezves, R. N., Modern Aspects of Electrochemistry, Vol. 9, J. O'M. Bockris and B. E. Conway eds. (Plenum Press, New York) 1974.

[46] Bockris, J. O'M. and HABID, M. A., Electrochim. Acta, in press.

[47] Cooper, I. L. and Hanson, J. A., v. Electroanal. Chem. 66 (1975) 85.

[48] Verkroost, A. W., Sluyters-Rehbach, M. and SluyTERS, J. H., ibid. 24 (1970) 1.

[49] PAXne, R., J. Electrochem. Soc. 113 (1966) 999.

[50] Payne, R., Trans. Faraday Soc. 64 (1968) 1638.

[51] Payne, R., The Electrical Double Layer in Non-aqueous Solutions, in Advances in Electrochemistry and Electrochemical Engineering, Vol. 7, P. Delahay and E. Tobias, eds. (J. Wiley and Sons, New York) 1970.

[52] Bewick, A. and Robinson, J., J. Electroanal. Chem. 71 (1976) 131 , ibid. 60 (1975) 163.

[53] Leban, M. A. and Hubbard, A. T., J. Electroanal. Chem. 74 (1976) 253.

[54] Hamelin, A. and Valette, G., C. R. Hebd. Séan. Acad. Sci. 269C (1969) 1020.

[55] Vitanov, T., Sevast'yanov, E. S., Bostanov, V. and Budewski, E., Elektrokhimiya 5 (1969) 451.

[56] Giles, R. D. and Harrison, J. A., J. Electroanal. Chem. 24 (1970) 399.

[57] Diggle, J. W. and LovreceK, B., ibid. 24 (1970) 119. 
[58] Hamelin, A. and Lecceur, J., Collect, Czech. Chem. Commun. 36 (1971) 714.

[59] Huong, N. V. and Clavilier, J., C. R. Hebd. Séan. Acad. Sci. 272C (1971) 1404.

[60] Hameln, A. and DeChY, P., ibid. 272C (1971) 1450

[61] Randin, J. P. and Yeager, E.. J. Electrochem. Soc. 118 (1971) 711.

[62] Randin, J. P. and Yeager, E., J. Electroanal. Chem. 36 (1972) 257.

[63] Huang, J. C., O'Grady, W. E. and Yeager, E., J. Electrochem. Soc., in press.

[64] Angerstein-Kozlowska, H., Sharp, W. B. A. and Conway, B. E., Proceedings of Symposium on Electrocatalysis, M. W. Breiter, ed. (The Electrochemical Society, Princeton, N. J.) 1974, p. 94.

[65] WILL, F., v. Electrochem. Soc. 112 (1965) 451.

[66] Bronel, G., Haim, M., Pesant, J. and Peslerbe, G.. Surf. Sci. 61 (1976) 29.

[67] Kinoshita K. and Stonehart P., Electrochimie. Acta 20 (1975) 101

[68] Bagotszky, V. S., Vassiliev, Yu. B. and Pyshnograeva, J. I., Electrochim. Acta 16 (1971) 2141.

[69] McInTyre, J. D. E. and Kolb, D. M., Symp. Faraday Soc. 4 (1970) 99.

[70] Bewick, A. and Tuxford, A. M., ibid.4(1970) 114.

[71] Schultze, J. W. and DickertmanN, D., Surf. Sci. 54 (1976) 489.

[72'] Kolb, D. M., Przasnyski, M. and Gerischer, H., J. Electroanal. Chem. 54 (1974) 25.

[73] Vicente, V. A. and Bruckenstein, S., 4nal. Chem. 45 (1973) 2036.

[74] Tindall, G. W. and Bruckenstein, S., Electrochim. Acta 16 (1971) 245 .

[75] Gerischer, H., Kolb, D. M. and PrZASNYSKI, Surf. Sci. 43 (1974) 662.
[76] ADZIC, R, YEAGER, E and CAHAN, B. D., J. Electrochem. Soc. 121 (1974) 474 ; 121 (1974) 1611.

[77] Horkans, J., Cahan, B. D. and Yeager, E., ibid. 122 (1975) 1585.

[78] Astley, D. J., Harrison, J. A. and Thirsk, H. R., J. Electroanal. Chem. 19 (1968) 325.

[79] Adzic, R. R. and Despic, A. R., v. Chem. Phys. 61 (1974) 3482 .

[80] Adzic, R. R., Simic, D. N., Drazic, D. M. and Despic, A. R., v. Electroanal. Chem. 61 (1975) 117.

[81] Gerlach, R. L. and Rhodin, T. N., Surf. Sci. 17 (1969) 32 ; 19 (1970) 403.

[82] Polanski, J. and Sidorskx, Z., Surf. Sci. 40 (1973) 282.

[83] Henrion, J. and Rhead, G. E., Surf. Sci. 29 (1972) 20.

[84] Perdereau, J. and Szymerska, J., Surf. Sci. 32 (1972) 247.

[85] Delamare, F. and Rhead, G. E., Surf. Sci. 35 (1973) 172.

[86] SchmidT, L. D. and Gomer, R., J. Chem. Phys. 42 (1970) 705.

[87] GadzuK, J. W., Phys. Rev. B 1 (1970) 2110.

[88] GadzuK, J. W., Surf. Sci. 6 (1967) 133.

[89] Lorentz, W., Hermann, H., Würthrich, N. and HiLBERT, F., J. Electrochem. Soc. 121 (1974) 1167.

[90] Bowles, B. J. and Cranshaw, I. E., Phys, Lett. 17 (1965) 258.

[91] Takamura, T., Takamura, K., NipPe, W. and Yeager, E., J. Electrochem. Soc. 117 (1970) 626.

[92] McIntYre, J. D. E. and KolB, D. M., Symp. Faraday Soc. 4 (1970) 99.

[93] Kolb, D. M., Leutloff, D. and Przasnyski, M., Surf. Sci. 47 (1975) 622.

[94] Takamura, T., Sato, Y. and Takamura, K., J. Electroanal. Chem. 11 (1973) 31.

[95] Conway, B. E., in Electrocatalysis on Non-Metallic Surfaces, NBS Special Publication 455, U. S. Dept. of Commerce Washington, 1976, pp. 107-124.

\section{DISCUSSION}

QUENTEL. - Comment obtenez-vous vos surfaces monocristallines ? Quel est votre support de départ ? En LEED observez-vous des surstructures ? En Auger quels sont les pics restants ?

YEAGER. - The platinum single crystal electrode involved in the hydrogen adsorption studies were prepared by high-temperature annealing combined with argon ion sputtering to clean the surfaces. The procedure is described in a recent publication (O-GRADY, W., Woo, M., Hagans, P. and Yeager, E., J. Vac. Sci. Technol. 14 (1977) 365). Auger spectroscopy was used to establish that the surfaces were free of any impurites, particularly carbon. LEED was used to establish the surface structure before the transfer from the $10^{-10}$ torr vacuum into the electrochemical environment within the thin-layer electrochemical cell. The use of $\mathrm{H}_{2} \mathrm{SO}_{4}$ as the electrolyte interfered with the re-examination of the surfaces with LEED after the electrochemical measurements, but we plan to use a completely volatilizable electrolyte (dilute HF) in future studies so as to be able to carry out such post examination with LEED.

Epelborn. - 1. Pendant longtemps le dialogue entre électrochimistes et opticiens était difficile car les premiers utilisaient dans l'étude de la structure de la double couche l'impédance électrochimique d'une électrode à goutte de mercure type Heyrovski bien défnie chimiquement mais inutilisable en spectroscopie optique car la surface métallique est contamment renouvelable. En modulant dans un large domaine de fréquence $\left(10^{-4} \mathrm{~Hz}\right.$ à $\left.10^{5} \mathrm{~Hz}\right)$ la polarisation de l'électrode solide on peut définir une impédance électrooptique et la comparer avec l'impédance électrochimique. Le pr. E. Yeager qui est un pionier de ces impédances électrooptiques a-t-il une opinion sur les perspectives de cette méthode dans l'étude des interfaces solide-liquide?

2. Les électrochimistes s'intéressaient surtout à la décharge de l'hydrogène qui est un problème trop complexe pour servir de point de rencontre avec les opticiens. Actuellement les physico-chimistes des interfaces métal-gaz et métal-solution aqueuse trouvent qu'il existe plusieurs espèces d'hydrogènes adsorbés. Cet accord est-il purement formel ou peut-on envisager des analogies entre ces processus ?

Yeager. - 1. I agree with Professor Epelboin that optical electrochemical impedance methods are powerful tools for the study of electrochemical interfaces, particularly adsorption-desorption processes and va- 
rious types of layers. I did not discuss these in my lecture since Dr. R. Adzic will discuss them later in this colloquium. We have used them to examine the kinetics of ion adsorption-desorption [ADzIC, R., Cahan, B. and Yeager, E., J. Chem. Phys. 58 (1973) $1780]$ and also the properties of the passivation film on iron [Wheeler, D., CAHAN, B. and Yeager, E., National Meeting, Electrochemical Society, Philadelphia (May 1977); to be submitted for publication]. All of our measurements have been made with modulation frequencies of a few hertz to $10^{4} \mathrm{~Hz}$. The much wider range $\left(10^{-4}\right.$ to $\left.10^{5} \mathrm{~Hz}\right)$ mentioned in your comment should prove quite interesting although such low frequencies as $10^{-4} \mathrm{~Hz}$ may result in substantial interpretative as well as experimental problems (e. g., the need for long-term stability in the optical-electrochemical system).

2. The comparison of the adsorption of hydrogen and other species at metal-gas and metal-electrolyte interfaces is worthwhile on well characterized single crystal surfaces. Care must be exercised not to overinterprete such comparisons, however, since the electrochemical interface has special features - particulary the electric field and the competitive interaction of the various electrolyte phase components with the electrode surface.

To some extent there are similarities between thermal and flash desorption-experiments at the metal vacuum interface and electrochemical desorption in linear sweep voltammetry. The comparison is probably valid only when the interactions of the metal and adsorbed species on the surface with electrolyte components are weak and the adsorbed species have very little ionic character. Hydrogen adsorbed on Pt may come close to fulfilling these conditions.

LÜrH. - A question to the combined experiment : ultrahigh vacuum-solid/liquid. Why do you use argon for covering the metal surface prepared in ultrahigh vacuum before bringing it in contact with the liquid interface ? Can't you just cover the clean surface by a molecular beam of water molecules ?

YEAGER. - The objective of our work with LEED and Auger has been to examine the properties of the electrochemical interfaces using clean electrode surfaces of known surface structure. Consequently it is necessary to bring a bulk electrolyte in contact with the surface and control the potential drop across the interface : This leads to the use of an inert ultrapure gas (99.999 $9 \%$ argon) during the electrochemical measurements. Perhaps experiments can be devised with very low vapor pressure electrolytes (e. g. supercooled liquid electrolytes at low temperatures) but we have not attempted such.

The experiment you suggest with a molecular beam of water molecules is interesting as a means for gaining information concerning the interaction of water with the electrode surfaces. The adsorption of water vapor on single crystal metal surfaces has been investigated by other workers, [see e. g. IshiKawa, R. and HubBARD, A., J. Electroanal. Chem. 69 (1976) 317].

KRUGER. - I would like to point out that the possibility of the introduction of surfaces inhomogeneities in electrochemical systems is very strong. For example, Dr. Melmed in a recent publication in Surface Science has shown by field ion microscopy that hydrogen causes inhomogeneities in the surface of $T i$ at specific crystallographic sites. These lattice disturbances extend at least 15 atomic layers below the surface.

YEAGER. - I doubt if hydrogen adsorption on single crystal Pt produces such extreme effects as you mention for Ti, although we can not rule out such possibilities at this stage in our work. The reproducibility of the voltammetry curves for hydrogen adsorptiondesorption upon repeated cycling in the hydrogen potential range is evidence against such. We may gain further insight when we have been able to re-examine the LEED patterns following the electrochemical experiments, as mentioned in my reply to an earlier question.

Costa. - Peut-on admettre que la constante diélectrique de la couche d'eau fixée à la surface a une constante diélectrique réelle c'est-à-dire que sa partie imaginaire est nulle?

YEAGER. - To answer your question requires a knowledge of the relaxation spectrum for water in the compact layer. The relaxation frequency for this water is probably well below that for bulk water but too high for reliable capacitance measurements. Some workers have reported dispersion in capacitance measurements on $\mathrm{Hg}$ at frequencies below $10^{6} \mathrm{~Hz}$ but I believe that such dispersion may be the result of experimental artifacts. Experiments above $10^{6} \mathrm{~Hz}$ are very difficult.

In the frame-work of Parson's four state version of the Damaskin-Frumkin model, the structural relaxation in the compact layer can be presented as follows :

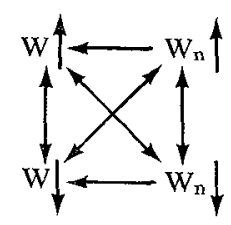

where the symbols have the significance indicated in my lecture. There should be three non-trivial relaxation times for this array with the longest determined principally by the activation barrier for disrupting the interaction of the water oxygen with the electrode surface, at least for transition metals with high heats of wetting.

In my opinion, a metal such as $\mathrm{Cu}$ or $\mathrm{Ni}$ would provide the best opportunity for a low frequency observable relaxation. The experiments would require vapor deposited metal surfaces of extreme flatness in a highly 
idealized geometry to avoid experimental artifacts but might provide interesting results.

PLIETH. - Several of the models of the double layers shown in Professor Yeager's talk were static models. This is especially true for the Brockris model. Therefore, one should point out that there is also a dynamics in the surface including vibrations and at least for liquid electrodes motions of the metal atoms as well as of the molecules in the electrolyte. Thus even in static models one should think of statistical distributions rather than of single values for any surfaee properties. Statistical distributions are not only characterized by their mean values but also by their width. Furthermore, relaxation problems arise in the establishment of an equilibrium distribution.

For the electrolyte a statistical description was given by Gurney and later on by Gerischer. For the double layer, statistical models were described e. g. Kirkwood and Stillinger. A statistical picture for adsorbed molecules was described e. g. by Plieth and Vetter.

I think, especially in optical measurements, these statistical pictures are of importance. Optical properties are in fact statistical values or in the continuum limit, continuous values. Thus the static as well as kinetic characteristics of the distribution function will be reflected in the optical properties.

YeAGER. - The most recent treatment of Bockris and Habib as well as those of Damaskin and Parsons, cited in my lecture, use statistical thermodynamics to describe the equilibrium conditions with 3 or 4 state models for water in the compact layer. These treatments do predict the dependence of the equilibrium on such valuables as temperature and potential but do not predict the relaxational properties or widths of the statistical distributions. Since we do not have adequate models to predict the structural and dielectric relaxational properties of even bulk water, I doubt if any of the dynamic models so far developed for the double layer using statistical mechanics are very quantitative. We must first quantify the interactions of the water molecules with the surface, including the potential energy surfaces for adsorption-desorption and reorientation. This is indeed difficult.

The eloguent treatment of Buff and Stillinger to which you refer unfortunately has severe limitations, as I mentioned in my paper.

The vibrational properties of the surface atoms of the electrode phase probably do influence the compact layer properties but I believe their effects on the equilibrium state of this layer are small and hence can be omitted from the statistical thermodynamic treatments with little error, at least with heavier metals such as $\mathrm{Hg}$.

ADZIC. - Your curves for hydrogen adsorption on $\mathrm{Pt}$ in the presence of specifically adsorbed halides show a change of the position of peaks on the potential axis. Can you give some explanations of that behaviour ?
YeAGer. - The hydrogen voltammetry peaks are shifted in potential by the addition of specifically adsorbed anions such as $\mathrm{Cl}^{-}$and $\mathrm{Br}^{-}$with the shift dependent on the concentration of the specifically adsorbed ions [HuanG, J., O'Grady, W. and YeaGER, E., v. Electrochem. Soc., in press]. With $\mathrm{Br}^{-}$and $\mathrm{Cl}^{-}$, the shift involves principally the strongly adsorbed hydrogen peak with the shift towards more cathodic potentials and dependent on the logarithm of the bulk phase concentration of the anion. This effect can be explained on the basis of the shift of the potential of zero charge (the Esin-Marhov effect) which falls in the midst of the hydrogen region for $\mathbf{P t}$ in acid solutions. The adsorption-desorption of hydrogen in the strongly adsorbed peak (IV) is probably coupled with the desorption-adsorption of halide and visa versa for the system represented in figure 12 of my lecture. I do not believe it a simple blocking effect.

Shumilova N. - What is your opinion, Professor Yeager, about the possibility to identify the nature of particles using ellipsometry?

Yeager. - You raise an important point since one of the important contributions which can be made by optics to electrochemistry is the identification of adsorbed species and layers at electrode surface. When localized valency states are involved, ultraviolet-visible specular or diffuse reflectance and ellipsometric spectroscopy may yield the electronic absorption spectra of the species adsorbed on the electrode or in an electrocatalyst and passivation layers. This can help to establish valency state, changes in conjugation in organic species, etc. While we do not understand all the features of Raman scattering at electrode surfaces, nonetheless there is evidence that Raman can yield information concerning the vibrational spectra of adsorbed species and foreign layers. Also ultravioletvisible, Raman and fluorescence can help to identify solution phase intermediates. This has been well demonstrated by various electrochemical groups including those of Kuwana, Winograd and Van Duyne.

NABGele (Comment). - I would like to point out that $I$ do not believe in the utility of substituting the commonly used three phase model by some kind of stratified phase system. Due to the fact that Maxwell theory requires sharp phase boundaries, I cannot understand how in a region of perhaps $10 \AA$ or even less, such equations should give better insight into the phenomena. What we can get of an optical experiment is some kind of collective response of all matter involved in the interface region to the incident light. To split up this response, one needs quantum-theoretical calculations of each effect in the way Professor Dogonadze proposed in yesterday's session.

YEAGER. - I agree with you that the five-layer model has serious draw-backs and in general is not very useful. From optical measurements it is not possible to 
establish the position relative to the interface from which particular contributions to the measured optical properties originate, for distances very small compared to the wavelength. If a theory is available which predicts the spatial dependence of the optical properties, a stratified optical model may be acceptable but optical measurements can only be used to test the spatially integrated features of the model. This may still be useful, as for example, in the treatment of the diffuse ionic layer, the space charge region of semiconductor electrodes and the passivation layer under some conditions. 